\title{
Two-Photon Transitions in Quadrupolar and Branched Chromophores: Experiment and Theory
}

\author{
Claudine Katan, ${ }^{*}, \uparrow$ Sergei Tretiak, ${ }^{\dagger, \ddagger}$ Martinus H. V. Werts, ${ }^{\dagger}$ Angus J. Bain,,$\S$ \\ Richard J. Marsh, ${ }^{\S}$ Nicholas Leonczek, ${ }^{\S}$ Nicholas Nicolaou, ${ }^{\S}$ Ekaterina Badaeva,, \\ Olivier Mongin, ${ }^{\dagger}$ and Mireille Blanchard-Desce*, ${ }^{*}$
}

Synthèse et ElectroSynthèse Organiques (CNRS, UMR 6510), Université de Rennes 1, Campus de Beaulieu, Bât 10A Case 1003, F-35042 Rennes Cedex, France, Department of Physics and Astronomy, University College London, Gower Street, London WC1E 6BT, U.K., Department of Chemistry, University of Washington, Seattle, Washington 98195-1700, and Los Alamos National Laboratory, Theoretical Division, Center for Nonlinear Studies (CNLS), and Center for Integrated Nanotechnologies (CINT), Los Alamos, New Mexico 87545

Received: February 7, 2007; In Final Form: May 25, 2007

\begin{abstract}
A combined experimental and theoretical study is conducted on a series of model compounds in order to assess the combined role of branching and charge symmetry on absorption, photoluminescence, and twophoton absorption (TPA) properties. The main issue of this study is to examine how branching of quadrupolar chomophores can lead to different consequences as compared to branching of dipolar chromophores. Hence, three structurally related $\pi$-conjugated quadrupolar chromophores symmetrically substituted with donor end groups and one branched structure built from the assembly of three quadrupolar branches via a common donor moiety are used as model compounds. Their photophysical properties are studied using UV-vis spectroscopy, and the TPA spectra are determined through two-photon excited fluorescence experiments using femtosecond pulses in the 500-1000 nm range. Experimental studies are complemented by theoretical calculations. The applied theoretical methodology is based on time-dependent density functional theory, the Frenkel exciton model, and analysis in terms of the natural transition orbitals of relevant electronic states. Theory reveals that a symmetrical intramolecular charge transfer from the terminal donating groups to the middle of the molecule takes place in all quadrupolar chromophores upon photoexcitation. In contrast, branching via a central electron-donating triphenylamine moiety breaks the quadrupolar symmetry of the branches. Consequently, all Frank-Condon excited states have significant asymmetric multidimensional charge-transfer character upon excitation. Subsequent vibrational relaxation of the branched chromophore in the excited state leads to a localization of the excitation and fluorescence stemming from a single branch. As opposed to what was earlier observed when dipolar chromophores are branched via the same common electron-donating moiety, we find only a slight enhancement of the maximum TPA response of the branched compound with respect to an additive contribution of its quadrupolar branches. In contrast, substantial modifications of the spectral shape are observed. This is attributed to the subtle interplay of interbranch electronic coupling and asymmetry caused by branching.
\end{abstract}

\section{Introduction}

Among the numerous nonlinear optical (NLO) processes, simultaneous absorption of two photons has gained increasing attention over recent years. ${ }^{1}$ In fact, two-photon absorption (TPA) opens the way for both improved and novel technological capabilities, such as multiphoton microscopy, ${ }^{2,3}$ optical limiting, ${ }^{4,5}$ and microfabrication. ${ }^{6-8}$ In the search for adequate materials for the various applications, organic molecular systems are of particularly interest due to their inherent modularity and the potentially high TPA response of conjugated systems. Indeed, over the past decade, an increasing effort has been devoted to the design of chromophores with enhanced TPA responses progressively moving from monomeric chromophores

* To whom correspondence should be addressed. E-mail: Claudine.Katan@univ-rennes1.fr (C.K.); Mireille.Blanchard-Desce@ univ-rennes1.fr (M.B.-D.).

†Université de Rennes 1.

Los Alamos National Laboratory.

§ University College London.

"University of Washington. such as dipoles ${ }^{9-15}$ and quadrupoles ${ }^{4,5,11,16-39}$ toward multimeric complex molecular architectures. ${ }^{40-62}$ Given the effort required to synthesize such compounds, thorough understanding of the various factors influencing the TPA response is highly desirable for the achievement of optimized TPA figures of merit.

Accumulated work in this field allows defining relevant aspects to which particular attention should be paid to avoid improper inferences about TPA responses. Investigations and analysis should not be limited to single wavelength data but rather span over the appropriate spectral region because spectral positions and band shapes are crucial for interpretation. ${ }^{47,63}$ Also, particular care should be taken in comparing and analyzing experimental data. For instance, nonlinear absorption measurements conducted in the nanosecond regime lead to "effective" TPA cross sections that may contain contribution of excited absorption occurring during the pulse duration. For this reason, experimental measurements should preferably be conducted in the femtosecond regime. Indeed, contributions from nonresonant linear absorption and from excited state absorption are known 


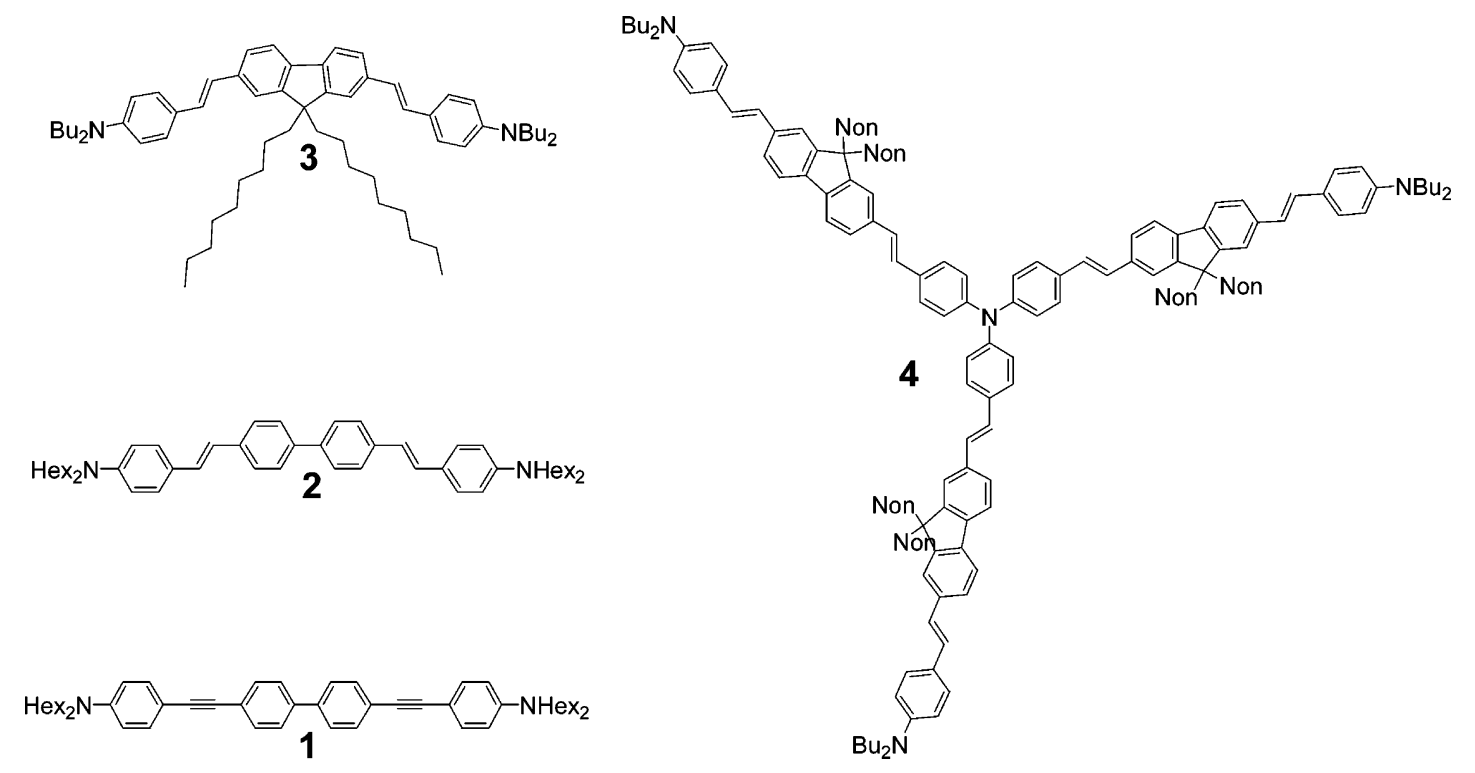

Figure 1. Series of quadrupolar $(\mathbf{1}-\mathbf{3})$ and branched (4) chromophores.

to lead to artificially enhanced effective TPA cross sections. ${ }^{18,64}$ Also, a proper discrimination between one-photon absorption and two-photon absorption contributions is of major importance when both phenomenon are occurring concomitantly. ${ }^{65}$

Among the different strategies implemented to obtain improved TPA responses, the branching strategy has received increasing attention over recent years. ${ }^{40-62}$ In multibranched systems, the interbranch coupling plays a central role. Depending on the extent and strength of this coupling, the ground state and the excited state will be either localized or delocalized, ${ }^{70}$ and optical properties such as TPA responses can show cooperative enhancement, ${ }^{41,45,50-52,62}$ additive behavior, ${ }^{43,44,57,71}$ or weakening. ${ }^{44}$ The nature and magnitude of the coupling depends on several structural parameters such as the nature, symmetry, and length of the conjugated branches and the nature of the branching moiety. ${ }^{72}$ These structural parameters actually define the ability for electronic delocalization and charge-transfer phenomena.

Analysis of the results of recent studies of the TPA properties of a series of branched chromophores built from the gathering of dipolar sub-chromophores via a common electroactive core moiety demonstrates that the TPA properties can be significantly affected by varying the connecting unit ${ }^{63,72}$ or the conjugated branch length. ${ }^{58,72}$ Indeed, the optical properties of multimeric dipolar chromophores can be either comparable ${ }^{72}$ or significantly different ${ }^{63}$ from those observed for their monomeric analogues. When dipolar branches are connected via an ambivalent (i.e., able to act either as a weak electron donor or a weak electron acceptor) triphenylbenzene (TPBenzene) core, it has been shown that the dipolar branches behave nearly as independent subchromophores. ${ }^{72}$ As a result, only small deviations from an additive behavior are observed on the absorption and TPA spectra. In contrast, triphenylamine (TPAmine) was shown to give rise to sizable electronic couplings between the dipolar branches, leading to noticeable TPA enhancement and spectral change. Such an effect can be qualitatively rationalized within the simple Frenkel exciton scheme ${ }^{73,74}$ which is responsible for the splitting of otherwise degenerate excited states. Interestingly, while only electrostatic interactions appear to contribute to the interbranch coupling in the case of multimeric systems built from a TPBenzene core (leading to weak TPA enhancement), ${ }^{72}$ other sources of couplings such as coherent interactions can be present when a TPAmine moiety is used as the branching unit. ${ }^{62,63,71}$

Interestingly, both branched systems built from a TPBenzene or TPAmine core were shown to lead to strongly dipolar emitting excited states as a result of the localization of the excitation on a single dipolar branch. ${ }^{63,71,72}$ It should be noted that experimental evidence of the localization of the excitation on a single branch prior to emission has been given for various branched systems built from a TPBenzene core. ${ }^{75-78}$

The aim of this work is to explore experimentally and theoretically how photophysical and TPA properties are modified by branching via a TPAmine core quadrupolar chromophores instead of dipolar chromophores. In that perspective, we first focus on the fluorescence and the one-photon absorption (OPA) and two-photon absorption (TPA) of a series of symmetrical quadrupolar chromophores bearing electron-donating end groups. We then select the quadrupolar chromophore that shows the most intense one- and two-photon absorption bands and investigate the effect of connecting these quadrupolar units via a common donating moiety. Earlier experimental investigations showed that the branching of quadrupolar systems in multimeric superstructures can indeed lead to a very large TPA response. ${ }^{22,45,48,49,51,55,56,62}$ However, the origin of the variation of the TPA response as compared to simple additivity, as well as to which structural parameters are involved, is still unclear. For instance, examination of the TPA responses of a series of conjugated dendrimeric systems ${ }^{45,62}$ built from slightly different short quadrupolar modules reveals different behaviors. A TPA cooperative enhancement is observed from generation 0 (threebranched compound) to generation 1 multimers built from TPAmine branching units connected by tolane connectors, in relation with a spatial extension of the coherence domain. ${ }^{62} \mathrm{~A}$ different behavior is observed in the case of multimers built from TPAmine branching units connected by stilbene connectors instead. ${ }^{45,51}$ Hence, for similar branching moieties, different behaviors are obtained depending on the nature of the quadrupoles and on the overall symmetry of the branching pattern. This clearly calls for a theoretical effort to provide a better understanding of the origin of TPA enhancements in branched structures built from quadrupolar building blocks.

Following this motivation, the present paper presents a combined theoretical and experimental study allowing for a 
detailed understanding of the photoluminescence and TPA properties of the series of molecules shown in Figure 1. These include quantum-chemical approaches centered on time-dependent density functional theory (TD-DFT), UV-vis spectra, fluorescence, fluorescence decay, and fluorescence anisotropy measurements as well as femtosecond two-photon excited fluorescence (TPEF) measurements. To investigate the wavelength dependence of the two-photon absorption cross section, two complementary experimental setups were used to span the visible-near-infrared (NIR) region from 560 to $980 \mathrm{~nm}$, significantly larger than the 700-1000 nm coverage provided by mode-locked femtosecond Ti:sapphire lasers. This allows for the observation of complete untruncated absorption bands, and additional spectral features at shorter wavelengths. Comparison to computational findings allows for interpretation over the whole spectrum especially for structural information on the transitions.

\section{Experimental and Computational Details}

2.1. Chromophores. The series (Figure 1) includes three quadrupolar molecules $\mathbf{1 - 3}$ and the branched structure (4) that bears three chromophores of type $\mathbf{3}$ connected via common nitrogen. The quadrupolar compounds are built from symmetrical functionalization of a biphenyl core that is either free (1 and 2) or planarized when using the dinonylfluorene core (3). Chromophore 1 was obtained by means of double Sonogashira coupling. ${ }^{22}$ Chromophores $\mathbf{2}$ and $\mathbf{3}$ were prepared via a double Wittig condensation carried out under solid-liquid phase transfer conditions. ${ }^{48,56}$ Branched structure $\mathbf{4}$ was obtained via a triple Horner-Wadsworth-Emmons condensation. ${ }^{49}$

2.2. Optical Absorption and Emission Spectroscopy. All photophysical properties have been performed with freshly prepared solutions of the chromophores in air-equilibrated toluene at room temperature $(298 \mathrm{~K})$. UV-vis absorption spectra were recorded on a Jasco V-570 spectrophotometer. Steady state and time-resolved fluorescence measurements were performed on dilute solutions (ca. $10^{-6} \mathrm{M}$, optical density $<0.1$ ) contained in standard $1 \mathrm{~cm}$ quartz cuvettes using an Edinburgh Instruments (FLS920) spectrometer in photon-counting mode. Emission spectra were obtained, for each compound, under excitation at the wavelength of the absorption maximum. Fluorescence quantum yields were measured according to literature procedures using fluorescein in $0.1 \mathrm{~N} \mathrm{NaOH}$ as a standard (quantum yield $\Phi=0.90) .{ }^{79,80}$ The lifetime values were obtained from the reconvolution fit analysis (Edinburgh F900 analysis software) of decay profiles obtained using the FLS920 instrument under excitation with a nitrogen-filled nanosecond flashlamp. The quality of the fits was evidenced by the reduced $\chi^{2}$ value $\left(\chi^{2}<\right.$ $1.1)$.

2.3. Two-Photon Excitation. Two-photon absorption cross sections $\left(\sigma_{2}\right)$ were determined from the two-photon excited fluorescence (TPEF) cross sections $\left(\sigma_{2} \Phi\right)$ and the fluorescence emission quantum yield $(\Phi)$. TPEF cross sections of $10^{-4} \mathrm{M}$ solutions were measured relative to known reference compounds (bis-MSB in cyclohexane for 560-700 $\mathrm{nm}^{81,82}$ and fluorescein in $0.01 \mathrm{M}$ aqueous $\mathrm{NaOH}$ for $700-980 \mathrm{~nm}^{83,84}$ ) using the wellestablished method described by $\mathrm{Xu}$ and $\mathrm{Webb}^{83}$ and the appropriate solvent-related refractive index corrections. ${ }^{85}$ The quadratic dependence of the fluorescence intensity on the excitation intensity was verified for each wavelength and each sample, indicating that the measurements were carried out in intensity regimes in which saturation or photodegradation do not occur. Two complementary setups were used to span the entire 560-980 $\mathrm{nm}$ range.
TABLE 1: Refined Reference Values for TPEF Action Cross Section Measurements (Fluorescein in $0.01 \mathrm{M} \mathrm{NaOH}$ )

\begin{tabular}{rcc}
\hline & \multicolumn{2}{c}{$\sigma_{2} \Phi / \mathrm{GM}$} \\
\cline { 2 - 3 }$\lambda(\mathrm{nm})$ & $\mathrm{Xu}$ and $\mathrm{Webb}^{83}$ & used in this work \\
\hline 700 & 17.1 & 11.3 \\
705 & & 11.7 \\
710 & 15.3 & 12.7 \\
715 & \multicolumn{2}{c}{ values by Xu and Webb }
\end{tabular}

The setup covering the 560-700 nm range is based on a regeneratively amplified Ti:sapphire-pumped tunable optical parametric amplifier delivering 200-250 fs pulses at a $250 \mathrm{kHz}$ repetition rate with an average power of $70 \mathrm{~mW} .86$ The output power was controlled using neutral density wheels and filtered using a range of long-pass filters to remove Ti:sapphire harmonics and residual continuum (Schott RD530-630). The on-sample powers typically varied between 10 and $100 \mu \mathrm{W}$. The OPA output was chopped at $220 \mathrm{~Hz}$ by an optical chopper (Stanford SR540), passed through a $2.5 \mathrm{~mm}$ aperture, and focused into a $50 \mu \mathrm{L}$ sample cuvette (Hellma) using a $25 \mathrm{~mm}$ achromatic lens (Melles Griot). The generated fluorescence was detected at $90^{\circ}$ using a $25 \mathrm{~mm}$ focal length lens and passed through an analyzing polarizer (Polaroid) set at $54.7^{\circ}$ to the excitation polarization (the magic angle). Scattered laser light was rejected by short pass filters (Schott LS550 and LS500 where appropriate); this was verified by the absence of signal when measuring cuvettes containing only solvent and detected by a photomultiplier (Hamamatsu 943-02) coupled to a lock-in amplifier (Stanford SRS 540). The fluorescence signals were corrected for differences in spectral overlap between the emitted fluorescence and the total sensitivity curve of the detection system.

For the 700-980 nm range, a Nd:YLF-pumped Ti:sapphire oscillator was used, generating $150 \mathrm{fs}$ pulses at a $76 \mathrm{MHz}$ rate. The excitation was focused into the cuvette through a microscope objective $(10 \times$, NA 0.25$)$. The fluorescence was detected in epifluorescence via a dichroic mirror (Chroma 675dcxru) and a barrier filter (Chroma e650sp-2p) by a compact CCD spectrometer module BWTek BTC112E. Total fluorescence intensities were obtained by integrating the corrected emission spectra measured by this spectrometer.

In order to obtain a smooth connection between the data points obtained using bis-MSB as a reference $(\leq 700 \mathrm{~nm})$ and those using fluorescein $(\geq 700 \mathrm{~nm})$, we found that it was necessary to refine the reference values for fluorescein between 700 and $720 \mathrm{~nm}$. The refinement was achieved by measuring the fluorescein TPEF cross sections using 4,4'-bis-(diphenylamino)stilbene (BDPAS) in $\mathrm{CH}_{2} \mathrm{Cl}_{2}$ as a reference. The absolute TPEF action cross section spectrum of BDPAS has been measured by Drobizhev et al., ${ }^{51,87}$ and represents a useful independent set of data. The refined TPEF cross sections of fluorescein used in the present paper are given in Table 1. The adjustment concerns only two data points in the original set of reference values, 700 and $710 \mathrm{~nm}$. A plot of the original and refined TPEF cross section spectra is included in Supporting Information Figure S3.

2.4. Computational Methods. Various quantum-chemical approaches have been employed to model all chromophores of interest, including their linear and nonlinear optical properties. For the sake of simplicity, nonyl, hexyl, and butyl solubilizing chains have been replaced by methyl groups. Solvation effects were neglected. Ground state optimized geometries have been obtained using the Gaussian 98 package ${ }^{88}$ For ground state geometries, we previously found that the Hartree-Fock (HF) 
TABLE 2: Calculated Electronic Quantities for Chromophores 1-4 Obtained at TD-B3LYP/6-31G//TD-HF/6-31G Levels ${ }^{a}$

\begin{tabular}{|c|c|c|c|c|c|c|c|c|c|c|c|c|}
\hline \multirow[b]{2}{*}{ state } & \multicolumn{3}{|c|}{1} & \multicolumn{3}{|c|}{2} & \multicolumn{3}{|c|}{3} & \multicolumn{3}{|c|}{4} \\
\hline & $|1\rangle$ & $|1\rangle^{(\mathrm{f})}$ & $|4\rangle$ & $|1\rangle$ & $|1\rangle^{(\mathrm{f})}$ & $|4\rangle$ & $|1 q\rangle$ & $|1 q\rangle^{(\mathrm{f})}$ & $|4 q\rangle$ & $|1\rangle,|2\rangle$ & $|1\rangle^{(\mathrm{f})}$ & $|4\rangle,|5\rangle$ \\
\hline$\Omega_{g e}^{b}(\mathrm{eV})$ & 3.34 & 2.74 & 4.32 & 3.22 & 2.55 & 4.03 & 3.06 & 2.55 & 4.08 & 2.78 & 2.36 & 3.08 \\
\hline$\mu_{g e}^{c}$ (D) & $13.2(x)$ & $16.3(x)$ & $7.5(x)$ & $13.1(x)$ & $17.1(x)$ & $6.7(x)$ & $13.4(x)$ & $16.2(x)$ & $5.9(x)$ & $15.1(x / y)$ & $18.5(x / y)$ & $5.6(x / y)$ \\
\hline$\mu_{g g}{ }^{d}(\mathrm{D})$ & 0.0 & 0.0 & & $0.16(z)$ & 0.0 & & $1.94(y)$ & $2.08(y)$ & & $1.18(z)$ & $3.05(z)$ & \\
\hline$\mu_{e e}{ }^{e}(\mathrm{D})$ & 0.0 & 0.0 & & $0.17(z)$ & 0.0 & & $3.94(y)$ & $3.17(y)$ & & $1.28(z)$ & $3.11(z)$ & \\
\hline
\end{tabular}

a Superscript "(f)" denotes the lowest excited state optimal geometry corresponding to fluorescence. Beyond the modulus of each dipole moment, the main polarization direction is indicated in parentheses. ${ }^{b}$ Transition frequency. ${ }^{c}$ Transition dipole moment. ${ }^{d}$ Ground state dipole moment. ${ }^{e}$ Excited state dipole moment.

method is superior to the DFT-based approaches by reproducing accurately bond length alternation parameters in similar conjugated systems when compared to experiment. ${ }^{63,89}$ Moreover, excited state geometry optimizations ${ }^{90,91}$ of substituted chromophores may fail due to long-range charge-transfer problems present in DFT. ${ }^{92-95}$ Thus, all ground state geometries are obtained at the HF level using the $6-31 \mathrm{G}$ basis set.

Hybrid functionals such as B3LYP have been found to be very accurate for excited states in many molecular systems. ${ }^{63,96-98}$ Consequently, we used the TD-B3LYP/6-31G level of theory to investigate linear and nonlinear optical properties using the density matrix formalism for nonlinear optical responses as described in ref 99. This method has already demonstrated its accuracy (within a factor of 6) for both linear and nonlinear absorption spectra in different series of substituted chromophores. ${ }^{57,63,89,100}$ Excited state electronic structures, with 20 excited states for compounds $\mathbf{1 - 3}$ and up to 54 for compound 4, were calculated with Gaussian 98 and 03 , respectively. ${ }^{88}$ Vertical transition frequencies $\left(\Omega_{g v}\right)$, dipoles $\left(\mu_{g v}\right)$, and densities $\left(\xi_{g v}\right)$ are used to model both linear absorption and TPA spectra. ${ }^{99}$ The linear absorption at frequency $\omega$ is given by the imaginary part of

$$
\alpha(\omega)=\sum_{v} \frac{f_{\mathrm{gv}}}{\Omega_{g v}^{2}-(\omega+i \Gamma)^{2}}
$$

where $\Gamma$ is the line width and $f_{g v}$ is the oscillator strength associated with the $|g\rangle$ to $|v\rangle$ electronic transition. The TPA cross section $\left(\sigma_{2}(\omega)\right)$ is related to the imaginary part of the thirdorder polarizability $(\gamma(-\omega ; \omega, \omega,-\omega))$ by

$$
\sigma_{2}(\omega)=\frac{24 \pi^{2} \hbar \omega^{2}}{n^{2} c^{2}} L^{4} \operatorname{Im}\langle\gamma\rangle
$$

where $\hbar$ is Plank's constant, $c$ is the speed of light, $n$ is the refractive index of the medium (for toluene, $n=1.494$ ), $L$ is the local field factor $\left(L=\left(n^{2}+2\right) / 3\right)$, and

$$
\langle\gamma\rangle=\frac{1}{15}\left(3 \sum_{i} \gamma_{i i i i}+\sum_{j \neq i}\left(\gamma_{i i j j}+\gamma_{i j i j}+\gamma_{i j j i}\right)\right)
$$

is the orientational average of $\gamma$ following eq 6 in ref 101 . $\gamma(-\omega ; \omega, \omega,-\omega)$ has been calculated using the density matrix formalism as described in ref 99. All comparisons with experiment for the amplitude of the responses are subject to an uncertainty in the choice of the line-broadening parameter $(\Gamma)$. In all calculations, we used an empirical line width of $\Gamma=0.1$ $\mathrm{eV}$.

To model fluorescence spectra, we used the TURBOMOLE ${ }^{102}$ package to optimize molecular geometries for the lowest excited state at the TD-HF/6-31G level. Thus, absorption and fluorescence points were treated within a consistent framework at the TD-B3LYP/6-31G//HF/6-31G and TD-B3LYP/6-31G//TD-HF/
6-31G levels, respectively, in conventional quantum-chemical notation "single point//optimization level". At excited state optimal geometry, transition frequencies $\left(\Omega_{g e}^{(f)}\right)$ and dipoles $\left(\mu_{g e}^{(f)}\right)$ corresponding to the vertical fluorescence process were used to calculate the radiative lifetime $\left(\tau_{0}\right)$ according to the Weisskopf-Wigner equation for the radiative decay rate: ${ }^{103}$

$$
\frac{1}{\tau_{0}}=\frac{1}{4 \pi \epsilon_{0}} \frac{4 \Omega_{g e}^{(f)^{3}} \mu_{g e}^{(f)^{2}}}{3 \hbar c^{3}} L
$$

where $\epsilon_{0}$ is the vacuum permittivity (MKS units) and $L$ accounts for local field effects.

We note that using DFT-based kernels (such as B3LYP) for ground state geometry optimizations would lead to consistent red shifts in the excitation energies and slightly increased OPA and TPA response amplitudes compared to the respective quantities calculated at the HF level.

Natural transition orbital analysis of the excited states ${ }^{104}$ has been further used to analyze the nature of the excited states involved in the photophysical processes. They offer the most compact representation of a given transition density in terms of an expansion into single-particle transitions. Figures showing molecular geometries and transition orbitals were obtained with XcrySDen. ${ }^{105}$

\section{Excited States and Two-Photon Absorption in Quadrupoles}

The three quadrupolar units $\mathbf{1 - 3}$ investigated in this study are sketched in Figure 1. Their ground state optimized geometries are more or less planar depending on the nature of the core and the spacer. The biphenyl core (1 and 2) and phenylene-vinylene spacer ( 2 and $\mathbf{3}$ ) introduces torsional degrees of freedom that lead to nonplanar optimal ground state (GS) geometries, with twist angles of about 43 and $39^{\circ}$ for compounds $\mathbf{1}$ and 2, respectively. All quadrupoles $\mathbf{1 - 3}$ nevertheless retain nearly centrosymmetric structures. This is also visible from both ground and excited state dipole moments calculated for the GS geometries: they are either vanishing (1) or rather small (2 and 3), when compared, for example, to corresponding transition dipole moments (Table 2).

Transition orbitals associated with vertical transitions between the ground state and the lowest excited states are shown for compound $\mathbf{3}$ in Figure 2, and provided as Supporting Information for compounds $\mathbf{1}$ and $\mathbf{2}$. Even if quadrupolar chromophores 1-3 do not have perfect inversion symmetry, their lowest excited state is predominantly one-photon allowed (OPA) while the second is predominantly two-photon allowed (TPA). Charge redistribution upon photoexcitation from the periphery to the core is observed for both excited states, but this effect is more pronounced in the second excited state associated with strong TPA. The following excited states (third and fourth) are predominantly TPA and OPA allowed, respectively, and correspond to different charge redistribution upon excitation. 


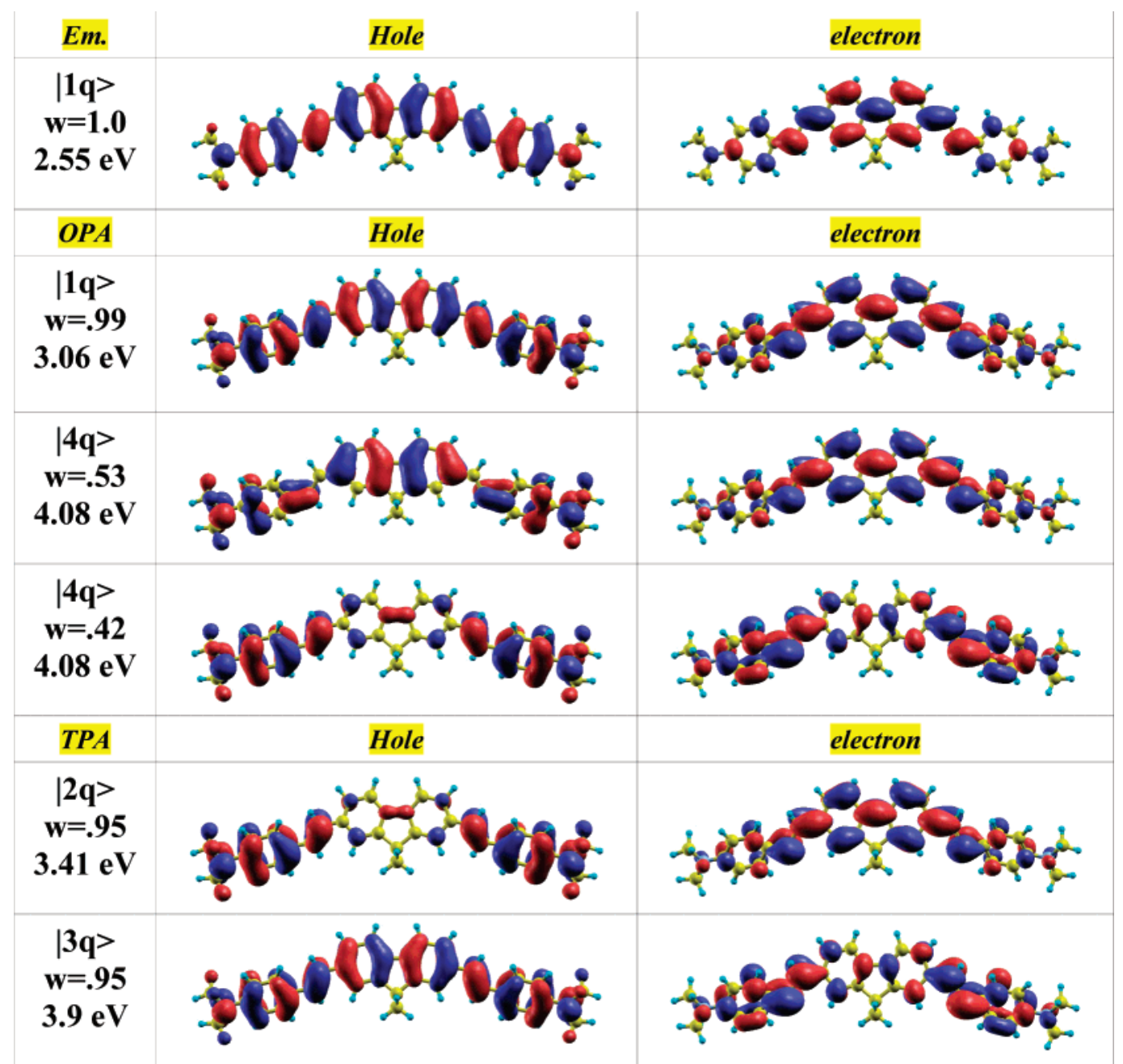

Figure 2. Natural transition orbitals ${ }^{104}$ of chromophore 3: emission (top panel); absorption (all others). The right panels quote in sequence excited state number, associated eigenvalues, and transition energies.

TABLE 3: Photophysical Data of Chromophores 1-4 in Toluene

\begin{tabular}{|c|c|c|c|c|c|c|c|c|c|c|c|c|c|}
\hline & $\begin{array}{c}\lambda_{\mathrm{abs}}^{\mathrm{expl} a} \\
(\mathrm{~nm})\end{array}$ & $\begin{array}{c}\lambda_{\text {abs }}^{\text {calcd } b} \\
(\mathrm{~nm})\end{array}$ & $\begin{array}{c}\epsilon_{\max }{ }^{c} \\
\left(\mathrm{~cm}^{-1} \mathrm{~mol}^{-1} \mathrm{~L}\right)\end{array}$ & $\begin{array}{l}\mathrm{fwhm} m^{d} \\
\left(\mathrm{~cm}^{-1}\right)\end{array}$ & $\begin{array}{c}\mu_{g e}^{\text {exptl } e} \\
\text { (D) }\end{array}$ & $\begin{array}{c}\mu_{g e}^{\text {calcd }_{f}} \\
\text { (D) }\end{array}$ & $\begin{array}{c}\lambda_{\text {em }}^{\text {exptl } g} \\
(\mathrm{~nm})\end{array}$ & $\begin{array}{c}\lambda_{\text {em }}^{\text {calcd } h} \\
(\mathrm{~nm})\end{array}$ & $\begin{array}{c}\text { Stokes } \\
\text { shift } \\
\left(\mathrm{cm}^{-1}\right)\end{array}$ & $\Phi^{i}$ & $\begin{array}{c}\tau^{\operatorname{expt~} j} \\
(\mathrm{~ns})\end{array}$ & $\begin{array}{c}\tau_{0}^{\text {exptl } k} \\
\text { (ns) }\end{array}$ & $\begin{array}{c}\tau_{0}^{\text {calcd } l} l \\
(\mathrm{~ns})\end{array}$ \\
\hline 1 & 374 & 370 & 83000 & 4400 & 9.1 & 13.2 & 424 & 452 & 3200 & 0.90 & 0.74 & 0.8 & 0.8 \\
\hline 2 & 401 & 385 & 83800 & 4100 & 9.2 & 13.1 & 456 & 486 & 3000 & 0.84 & 0.87 & 1.0 & 0.9 \\
\hline 3 & 415 & 405 & 96200 & 3800 & 9.6 & 13.4 & 457 & 486 & 2200 & 0.79 & 0.93 & 1.2 & 1.0 \\
\hline 4 & 428 & 445 & 245500 & 4000 & $11.3^{m}$ & $15.1^{m}$ & 471 & 526 & 2100 & 0.74 & 0.85 & 1.1 & 1.0 \\
\hline
\end{tabular}

${ }^{a}$ Experimental one-photon absorption maximum. ${ }^{b}$ Calculated one-photon vertical absorption maximum at the TD-B3LYP/6-31G//HF/6-31G level. ${ }^{c}$ Experimental molar extinction coefficient. ${ }^{d}$ Full width at half-maximum of the UV-vis absorption band. ${ }^{e}$ Transition dipole moment in vacuum derived from experiment. ${ }^{f}$ Calculated transition dipole moment in vacuum. ${ }^{g}$ Experimental one-photon emission maximum. ${ }^{h}$ Calculated one-photon vertical emission maximum at the TD-B3LYP/6-31G//TD-HF/6-31G level. ${ }^{i}$ Fluorescence quantum yield determined relative to fluorescein in $0.1 \mathrm{~N} \mathrm{NaOH} .{ }^{j}$ Experimental fluorescence lifetime determined using picosecond domain time-correlated single-photon counting (TCSPC). The excitation wavelengths for the single-photon excited lifetime measurements of compounds 1-4 were 470, 455, 400, and 470 nm, respectively. ${ }^{k}$ Radiative lifetime derived from fluorescence quantum yield and lifetime values $\left(\tau_{0}{ }^{\text {exptl }}=\tau_{\text {obsd }} / \Phi\right)$. ${ }^{l}$ Radiative lifetime derived from quantumchemical calculations using eq 4 (calculated at the TD-B3LYP/6-31G//TD-HF/6-31G level). ${ }^{m}$ For each of the two degenerate excited states.

The one-photon absorption and emission characteristics of chromophores $\mathbf{1 - 3}$ in toluene are summarized in Table 3 (and Supporting Information Figures S1 and S2) with their corresponding calculated values. Additional electronic quantities are given in Table 2. The overall agreement between experimental and theoretical values is quantitative except for transition dipole moments that are significantly overestimated by the calculations. This is a well-known problem within density functional methods based on current exchange potential functionals that affects hybrid functionals as well. ${ }^{106}$ The incorrect asymptotic behavior of the exchange-correlation potential leads to an overestimation of the charge transfer that increases with the molecular size. Nevertheless, given experimental and theoretical uncertainties, trends are well reproduced.

All chromophores show an intense absorption band in the near UV-violet region. As already known, replacement of the phenylene-ethynylene spacer (1) by the phenylene-vinylene unit (2) induces significant red shift of the absorption band. Additional replacement of the biphenyl core by a fluorene core (3) further increases this red shift due to increased conjugation in relation with the planarization of the core in the GS. ${ }^{56}$ The later substitution allows for a significant increase of the molar 
TABLE 4: Selected Bond Lengths for Chromophores 3 and 4 (in A) for Both Ground State (GS) and Relaxed Excited State (ES) Geometries ${ }^{a}$

\begin{tabular}{lccccc}
\hline & $\begin{array}{c}\text { central } \\
\mathrm{C}-\mathrm{C}\end{array}$ & $\begin{array}{c}\mathrm{C}-\mathrm{C} \text { next } \\
\text { to vinylene }\end{array}$ & $\begin{array}{c}\mathrm{C}=\mathrm{C} \text { of } \\
\text { vinylene }\end{array}$ & $\begin{array}{c}\text { central } \\
\mathrm{C}-\mathrm{N}\end{array}$ & $\begin{array}{c}\text { terminal } \\
\mathrm{C}-\mathrm{N}\end{array}$ \\
\hline 3-GS & 2.77 & 2.78 & 2.52 & 2.62 & 2.62 \\
4-GS & 2.77 & 2.78 & 2.52 & 2.68 & 2.62 \\
4-ES-B1 or B2 & 2.78 & 2.79 & 2.53 & 2.69 & 2.62 \\
4-ES-B3 & 2.69 & 2.73 & 2.58 & 2.67 & 2.62 \\
3-ES & 2.69 & 2.74 & 2.59 & 2.62 & 2.62
\end{tabular}

${ }^{a} \mathrm{~B} 1, \mathrm{~B} 2$, and B3 label the three different branches of molecule 4.

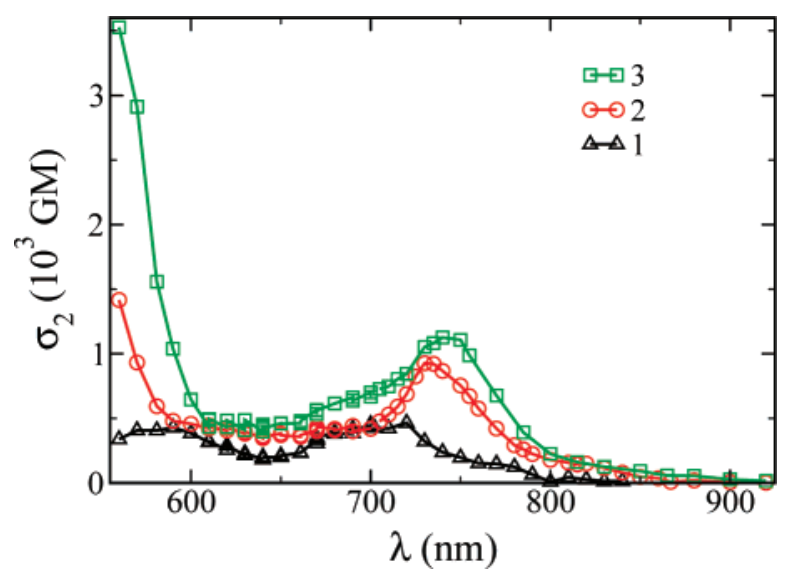

Figure 3. Experimental TPA cross section of quadrupolar compounds $\mathbf{1 - 3}$ in toluene.

extinction coefficients. However, a concomitant slight reduction of the bandwidth leads to a smaller increase of the transition dipole moment.

The lowest excited state (ES) optimal geometries of chromophores 1-3 indicate that the structure of the stilbenyl branches becomes planar with reduced bond length alternation (Figure 2 and Table 4; Supporting Information Figures S4 and S5). Due to additional planarization of the central biphenyl core observed for compounds $\mathbf{1}$ and $\mathbf{2}$, all three quadrupoles have fully planar ES geometries. As a result, emission spectra of fluorophores $\mathbf{2}$ and $\mathbf{3}$ are almost identical.

Similar to GS geometries, all quadrupoles $\mathbf{1}-\mathbf{3}$ have nearly centrosymmetric structures in the ES as well. Indeed, ground and excited state dipole moments calculated for the ES geometries are either vanishing or relatively small (Table 2). Chemical substitution along the series $\mathbf{1 - 3}$ leads to a slight increase of the radiative lifetime, well reproduced by the calculated values. As a consequence of the corresponding slight decrease of the radiative decay rates, the fluorescence quantum yields slightly decrease. Equation 4 and the data in Table 3 show that the increase of the radiative lifetime between $\mathbf{1}$ and $\mathbf{2}$ is mainly due to the red shift of the emission while that between $\mathbf{2}$ and $\mathbf{3}$ corresponds to a decrease of the transition dipole moment corresponding to the fluorescence process. This is indeed confirmed by the calculated values. However, the remarkable agreement between experimental and calculated values deserves some comments. In fact, it partly results from error cancellation of overestimated transition dipole moments and underestimated transition energies. In addition, solvent effects are accounted for by means of the Lorentz local field factor.

Experimental TPA spectra of quadrupolar compounds 1-3 are shown in Figure 3. The first TPA maximum of each of the three chromophores is significantly blue shifted with respect to twice the one-photon absorption maximum and shows up between 690 and $760 \mathrm{~nm}$. This is directly related to the nearly centrosymmetric molecular symmetry of these quadrupoles that brings the first excited electronic state to be almost TPA forbidden. However, the red shifts observed for the one-photon absorption spectra when going from chromophore $\mathbf{1}$ to $\mathbf{3}$ are observed for the different TPA peaks as well.

When analyzing the magnitude (i.e., maximum) of the first TPA band of chromophores of different structures, it is of particular interest to compare intrinsic TPA cross sections (i.e., normalized by the square of the effective number of electrons, determined using the counting method described in ref 107) as proposed by Kuzyk and co-workers. ${ }^{108}$ This provides a metric for comparison. In the case of chromophores $\mathbf{1 - 3}$, we observe that the intrinsic TPA is significantly increased on going from compound $\mathbf{1}$ to compound $\mathbf{3}$ (Table 5), although the molecules have the same effective number of electrons. This clearly is related to the nature of the connecting unit (double bond versus triple bond for chromophore 2 compared to chromophore 1) and of the core (fluorenyl versus biphenyl for chromophore $\mathbf{3}$ compared to chromophore 2). We observe that, unsurprisingly, this increase parallels both an increase of the transition dipole and a decrease of the energy gap between the ground and first excited state (Table 3 ) in agreement with increased conjugation. In addition, the enhancement of the intrinsic TPA is much stronger when replacing the vinyl linker by an ethynylene linker than by a biphenyl core (Figure 3), indicating that the lowering of the energy gap is correlated in that case with the intrinsic TPA magnitude.

All three chromophores show a second strong TPA band in the visible green-yellow region. Although these latter bands are closer to the one-photon resonances (Table 2), the two-photon excited fluorescence intensity still clearly varies as the square of the excitation power and no contributions from single-photon absorption were observed at these shorter wavelengths. Moreover, in the case of the strongest transition (compound 3), fluorescence anisotropies significantly in excess of 0.4 (the single-photon maximum) are observed together with a marked absorption anisotropy, $\Omega=\sigma^{(2)}{ }_{\text {circular }} / \sigma^{(2)}$ linear, indicating that this intense TPA band results from true TPA processes originating from the participation of higher-lying excited states. Polarized two-photon photoselection and the structure of the transition tensor will be discussed in detail in a forthcoming paper.

In fact, calculated TPA spectra (Figure 4) confirm these experimental findings. The TPA maximum in the NIR region can be assigned to the second excited state that undergoes significant charge transfer from the periphery to the core upon excitation (Figure 2). Virtual states involved in the TPA process are mainly the first and fourth excited states that bear significant oscillator strengths. Higher-lying excited states such as the third one (Figure 2) are responsible for significant TPA activity in the visible red region. Large TPA responses further to the blue (i.e., in the visible green region) are also predicted by calculations and correspond to excited states lying beyond the 10th excited state. An accurate description of these high-energy contributions would require incorporation of a very large number of excited states which explains the quantitative disagreement between calculated (Figure 4) and experimental data (Figure 3 ) in that spectral range.

Quantitative comparison between calculated and experimental TPA cross sections in the red-NIR region deserves some comments, as calculated values are systematically larger than experimental ones (Table 5). To begin with, calculations have been performed using a fixed line width of $0.1 \mathrm{eV}$ while experimental values are almost 3 times larger (Table 5). Also, as already mentioned, calculated transition dipole moments are 
TABLE 5: Two-Photon Absorption Cross Sections $\left(\sigma_{2}\right)$ and Transition Dipole Moments (gas Phase) in the NIR Region

\begin{tabular}{|c|c|c|c|c|c|c|c|c|c|c|c|}
\hline & $\begin{array}{c}2 \lambda^{\mathrm{OPA}_{\max }} \\
(\mathrm{nm})\end{array}$ & $\begin{array}{c}\lambda_{\max }^{\mathrm{TPA}} \\
(\mathrm{nm})\end{array}$ & $\begin{array}{l}\sigma_{2}{ }^{\text {exptl }} \\
(\mathrm{GM})\end{array}$ & $N_{\mathrm{eff}}^{a}$ & $\sigma_{2}{ }^{\text {exptt }} / N_{\text {eff }^{2 b}}$ & $\begin{array}{c}\lambda_{\max }^{\mathrm{TPA}} \\
(\mathrm{nm})\end{array}$ & $\begin{array}{l}\sigma_{2}^{\text {calcd }} \\
(\mathrm{GM})\end{array}$ & $\begin{array}{l}\mu_{e g}^{\text {exptl }} \\
\text { (D) }\end{array}$ & $\begin{array}{l}\mu_{e g}^{\text {calcd }} \\
\text { (D) }\end{array}$ & $\begin{array}{l}\Gamma^{\text {exptl }} \\
(\mathrm{eV})\end{array}$ & $\begin{array}{l}\sigma_{2}^{\text {corr } c} \\
(\mathrm{GM})\end{array}$ \\
\hline 1 & 748 & $\sim 700$ & $\sim 500$ & 28 & 0.64 & 682 & 6294 & 9.1 & 13.2 & 0.27 & 1100 \\
\hline 2 & 803 & 730 & 930 & 28 & 1.19 & 709 & 5880 & 9.2 & 13.1 & 0.25 & 1200 \\
\hline 3 & 830 & 740 & 1126 & 28 & 1.44 & 728 & 7404 & 9.6 & 13.4 & 0.24 & 1600 \\
\hline 4 & 856 & $735^{d}$ & $\mathbf{3 7 0 0}^{d}$ & 48.5 & 1.57 & $800^{d}$ & $14792^{d}$ & $11.3^{e}$ & $15.1^{e}$ & 0.25 & \\
\hline
\end{tabular}

${ }^{a}$ Effective number of $\pi$-electrons in the conjugated system defined according to ref $107 .{ }^{b}$ Intrinsic TPA cross section defined according to ref 108. ${ }^{c}$ Qualitative rescale of calculated TPA cross sections: correction for the overestimation of calculated transition dipole moments and for the fixed line width $\left(0.1 \mathrm{eV}\right.$ for all four chromophores) as derived from the ratio between experimental and theoretical values for $\left(\mu_{\mathrm{eg}}{ }^{2} / \Gamma\right) .{ }^{d}$ Experimental and calculated peaks are not directly comparable, as they do not necessarily belong to the same transitions. ${ }^{e}$ For each of the two degenerate excited states.

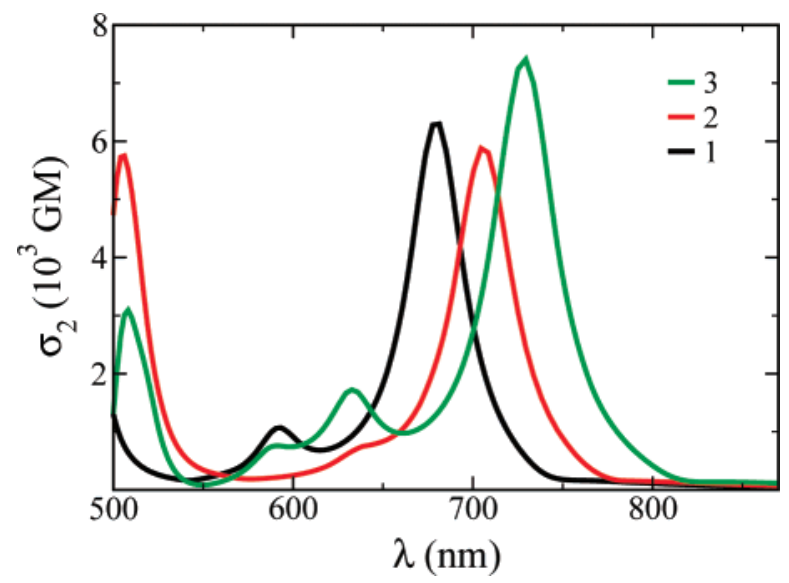

Figure 4. Calculated TPA cross section of chromophores 1-3.

systematically overestimated. On the basis of a simple threestate model, one can easily predict that both effects will induce a significant overestimation of the TPA cross sections. Within a three-state model, the main contribution to $\sigma_{2}$ is proportional to $\left(\mu_{\mathrm{eg}}{ }^{2} \mu_{\mathrm{ee}^{2}}{ }^{2} / \Gamma\right)$. Given that experimental $\mu_{\mathrm{ee}^{\prime}}$ are not available, a qualitative rescale can be obtained by considering the ratio between experimental and theoretical values for $\left(\mu_{\mathrm{eg}}^{2} / \Gamma\right)$. The corrected values given in the last column of Table 5 show a much better agreement with experimental values, both for the TPA increase along the series $\mathbf{1 - 3}$ and for the correct order of magnitude. In addition, it is important to notice that our calculations do not take into account vibrational contributions and solvent effects are limited to a Lorentz local field factor. We recently found that the way solvent effects are accounted for can indeed significantly modify the absolute calculated TPA magnitude. Thus, the deviation observed here may at least partly originate from the poor description of solvent effects. This will be discussed in detail in a forthcoming paper.

Both experiment and theory demonstrate that quadrupoles 1-3 also show very large TPA responses in the green-yellow part of the visible spectrum (Figures 3 and 4), due to the contribution of additional higher-lying two-photon allowed excited states. Quadrupole 3 which showed the highest TPA maximum cross section in the red-NIR region also shows the largest TPA cross section in the visible yellow-green region. Interestingly, the relative ranking in TPA activity in the quadrupolar series $\mathbf{1 - 3}$ is the same in the visible yellow-green region and in the visible red-NIR region. However, the differences in TPA response between chromophores $\mathbf{1}, \mathbf{2}$, and $\mathbf{3}$ are even more pronounced in that region. Indeed, chromophore 3 shows a TPA cross section at $560 \mathrm{~nm}$ of about $3500 \mathrm{GM}$ which is about 3 times larger that its maximum TPA cross section in the NIR. In comparison, chromophore $\mathbf{1}$ shows similar maximum TPA activity in the two distinct spectral regions (i.e., yellow-green and red-NIR) while chromophore 2 shows a TPA cross section at $560 \mathrm{~nm}$ which is $50 \%$ times larger than its maximum TPA cross section in the NIR (i.e., about $1500 \mathrm{GM}$ ).

Finally, quadrupole 3 shows the highest TPA cross sections over the entire investigated spectral range, leading to dramatically higher TPA responses in the green-yellow region. It is particularly interesting to observe that quadrupole $\mathbf{3}$ has also been shown to lead to the strongest optical limiting efficiency in the visible region. ${ }^{109}$ The present work indicates that its optical limiting efficiency in the visible green region might indeed be related to enhanced two-photon absorption. ${ }^{110}$

\section{Quadrupolar versus Branched Chromophores}

4.1. Geometry and Nature of the Excited States. The branching effect has been studied with model chromophore 4 that corresponds to the branching, via a common donating moiety, of three quadrupolar moieties 3 . The ground state optimal geometry of three-branched chromophore $\mathbf{4}$ shows geometrical parameters for each branch quasi-identical to those obtained for chromophore 3 (Table 4). The TPAmine central core leads to a propeller-like molecular shape where each branch is twisted by $45^{\circ}$ with respect to the plane defined by the nitrogen atoms and the three bonded carbon atoms. In a first step, this chromophore can be seen as an assembly of three quadrupolar monomers 3 that share a common nitrogen and $C_{3}$ symmetry can be assumed for the three-branched system. The Frenkel exciton model has been successfully used to treat several three-branched systems built from dipolar moieties. ${ }^{63,71}$ However, we find that the branched chromophore 4 shows a more complex picture. Within the Frenkel exciton model, the first excited state, $|1 q\rangle$, of the quadrupolar unit splits into three excited states as follows: a twofold degenerated first excited state which is both OPA and TPA allowed and red shifted by $-V$ ( $V$ corresponds to the electrostatic coupling between monomers), and a third, TPA allowed excited state is blue shifted by $+2 V$ (Figure 5). The same scheme can be applied to the monomer's second excited state, $|2 q\rangle$, with a coupling constant of $V^{\prime}$ instead of $V$ (Figure 5). Let us first investigate the validity of this simple excitonic scheme. Examination of the transition orbitals and respective excitation energies of compounds 3 (Figure 2) and 4 (Figure 6) leads to the following conclusions. In a very crude approximation, the three $|1 q\rangle$ states split into $(|1\rangle,|2\rangle)$ and $|6\rangle$ and the $|2 q\rangle$ states turn into $(|8\rangle,|9\rangle)$ and $|12\rangle$ in the branched system. The corresponding couplings are estimated to be 0.12 and $0.07 \mathrm{eV}$, respectively, but these splittings do not obey the $(-V,+2 V)$ splitting expected with respect to the transition energies of $|1 q\rangle$ or $|2 q\rangle$. Moreover, intermediate excited states are found. In fact, within this simple excitonic picture, state $|12\rangle$ should be the sixth excited state. A closer look into the transition orbitals clearly shows that the TPAmine core breaks the quadrupolar symmetry on each branch. This is especially visible on the holes of the plotted transition orbitals which are located either on one side (i.e., close to the 


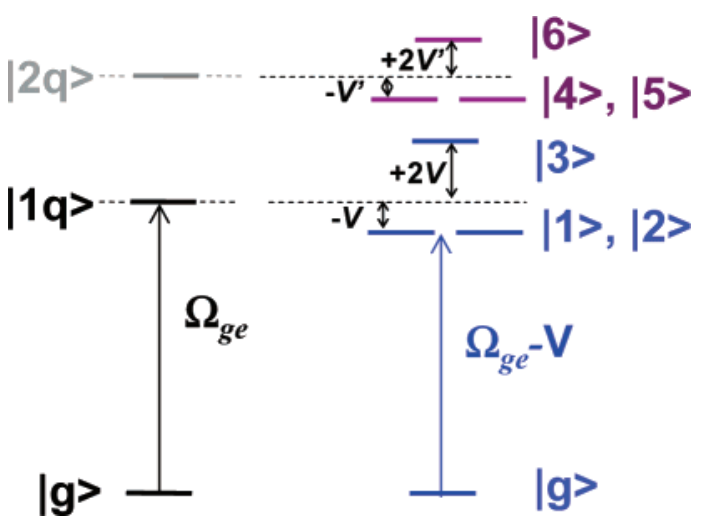

Figure 5. Schematic electronic level diagram of the quadrupolar chromophore (left) and a molecular model of $C_{3}$ symmetry built from gathering three quadrupolar branches (right) within the excitonic model. $|g\rangle$ denotes the ground state, $|n\rangle$ the $n$th excited state, $V\left(V^{\prime}\right)$ the interbranch coupling for the quadrupolar first (second) excited state $|1 q\rangle(|2 q\rangle)$.

molecule center; see, for example, state $|1\rangle$ ) or on the other side (i.e., on the molecule periphery; see, for example, state $|3\rangle)$ of each branch. The localization is less pronounced for the electrons of the transition orbitals. The dissymmetry introduced by the branching of three quadrupolar monomers via a shared donating end group clearly invalidates the use of the excitonic model for this type of trimer system because the quadrupolar branches lose their original symmetry in such a process. Such an effect is not observed when dipolar branches are assembled in the same way ${ }^{63}$ due to the absence of an intrinsic symmetry of the monomers.

Corresponding calculated absorption maxima and transition dipole moments are summarized in Table 3 (and Supporting Information Figures S1 and S2). Both the absorption and emission bands of the three-branched chromophore $\mathbf{4}$ are red shifted with respect to those of the corresponding quadrupolar branch 3. The experimental red shift of the OPA band corresponds to a decrease of the transition energy of $0.09 \mathrm{eV}$. The calculated value is about 3 times larger. This discrepancy is related to the well-known problem of the wrong asymptotic behavior of the exchange-correlation potential persistent even in hybrid kernels. This is especially evident for large molecules such as compound 4. Moreover, it does not correspond to a constant red shift of all excited states but depends on the characteristics of each excited state such as delocalization and charge-transfer features. Keeping this in mind, we use theoretical results obtained for compound $\mathbf{4}$ for qualitative rationalization of photophysical trends.

The branched molecule $\mathbf{4}$ shows a molar extinction coefficient approximately equal to 3 times that of compound $\mathbf{3}$, indicating a nearly additive behavior given the comparable bandwidths. Comparison of calculated oscillator strengths corroborates this finding. The emission properties of the branched system have been investigated as well. High fluorescence quantum yields are observed in the three-branched chromophore. As opposed to the case of branched systems resulting from the assembly of three dipolar chromophores via a common donor end group, where a noticeable increase of the fluorescence quantum yield is observed, ${ }^{63,71,72}$ a slight decrease of the fluorescence quantum yield is observed in our case. The Stokes shift found for compound $\mathbf{4}$ is comparable to that of compound $\mathbf{3}$, which indicates that comparable vibrational reorganization takes place after excitation and prior to emission. Geometry and transition orbitals of the first excited state are shown on the top panels of Figure 6. The relaxed excited state of the three-branched chromophore 4 does not retain the $C_{3}$-like symmetry. One branch adopts a planar geometry very close to that obtained for the relaxed first excited state of molecule $\mathbf{3}$, whereas the two other branches remain in the ground state geometry (Table 4). Transition orbitals representing the emitting excited state clearly show a localization of the excitation on one branch, compared to the corresponding Franck-Condon excited state. Both experimental and calculated radiative lifetimes are alike for chromophores $\mathbf{3}$ and $\mathbf{4}$, also confirming that emission does not stem from a delocalized excited state in the branched compound. The calculations demonstrate that localization of the excitation is mainly due to molecular vibrations. Here, solvation interaction can be ruled out due to the quadrupolar nature of the branches and the non-dipolar nature of the chosen solvent (toluene). The break of quadrupolar symmetry is still quite pronounced for the emitting state. Indeed, both calculated and experimental emission maxima are significantly red shifted with respect to those of the quadrupolar branch 3 (Table 3).

The phenomenon of localization of excitation is a general characteristic of such branched systems. The excitation localization on one branch of a trimeric system has already been proven by photophysical experiments conducted on octupolar derivatives built from the TPAmine core ${ }^{61,63,71}$ and on three-branched systems and conjugated dendrimers built from various joints/ cores. ${ }^{61-63,70,77}$

4.2. Two-Photon Absorption. The experimental TPA spectrum of compound 4, reported in Figure 7, shows a broad band in the NIR region. The TPA maximum is significantly blue shifted with respect to twice the one-photon absorption maximum (Table 5; Supporting Information Figure S6). Calculated TPA cross sections reported in Figure 8 show the same features (Supporting Information Figure S6). Although the simple excitonic picture does not apply here, this is a feature also observed in three-branched chromophores for which the first two (degenerated) excited states (red shifted with respect to the first excited state of the branch) show little TPA activity while the third excited state (blue shifted with respect to the first excited state of the branch) is strongly two-photon allowed. ${ }^{63,71}$ Concerning the TPA amplitude, a systematic overestimation of calculated values when compared to experimental ones is observed. As for the quadrupolar compounds discussed in the previous section, this is very likely related to both the overestimation of the transition dipole moments (Table 5) and the underestimation of the line width (typically more than twice too small, here $0.1 \mathrm{eV}$ instead of about $0.25 \mathrm{eV}$ ). In addition, vibrational effects are neglected and solvent effects are accounted for by a simple local field factor.

Surprisingly, one observes a noteworthy correspondence between some states of quadrupole 3 and branched system 4 . The OPA state $|1 q\rangle$ and the TPA state $|3\rangle$ as well as the TPA states $|2 q\rangle$ and $|12\rangle$ have almost the same transition energies (Figure 5). In addition, transition orbitals associated to state $|12\rangle$ are on each of the three branches very similar to that of state $|2 q\rangle$ and show almost no dissymmetry with respect to the center of each branch. Interestingly, chromophore $\mathbf{4}$ shows a TPA maximum in the NIR region located at almost the same position as the lowest-energy TPA maximum of quadrupole $\mathbf{3}$ (Figure 9 and Table 5). At the same time, a shoulder is observed in the experimental TPA spectrum of branched compound $\mathbf{4}$ around $800 \mathrm{~nm}$, that is, close to twice the OPA maximum of quadrupolar chromophore 3 (which corresponds to the lowest-energy one-photon allowed but two-photon forbidden excited state in quadrupole 3: $(|1 q\rangle)$, suggesting that the breaking of centrosym- 


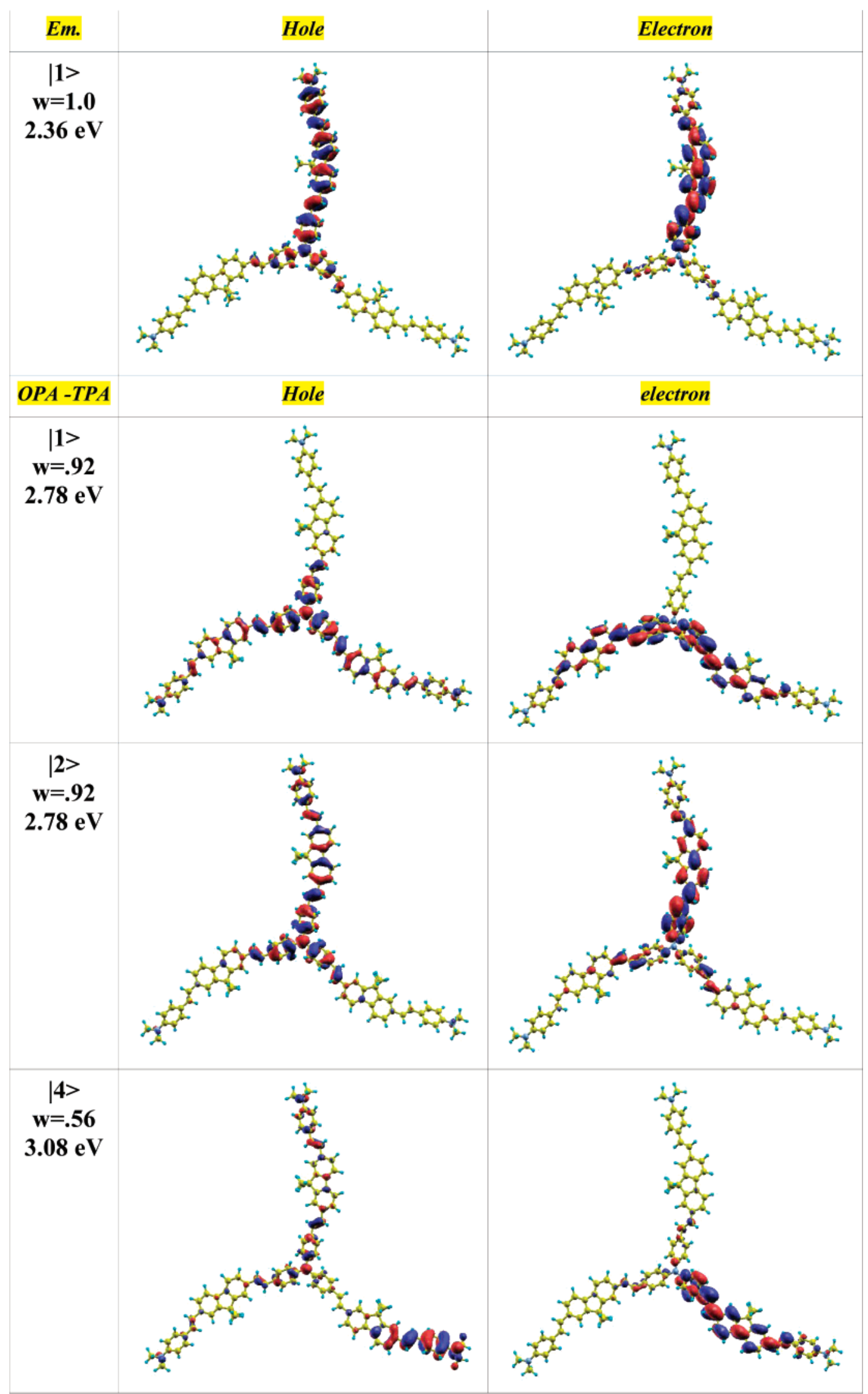

Figure 6. Part 1 of 4.

metry of the quadrupolar branch when incorporated in the threebranched geometry leads to two-photon allowed excited states.

These correlations may or may not be fortuitous. Given the size of the branched chromophore and the huge number of excited states involved, it is difficult to conclude unambiguously. In fact, the poor description of the long-range Coulomb electron-electron interactions already mentioned leads to a significant red shift of calculated transition energies, at least 


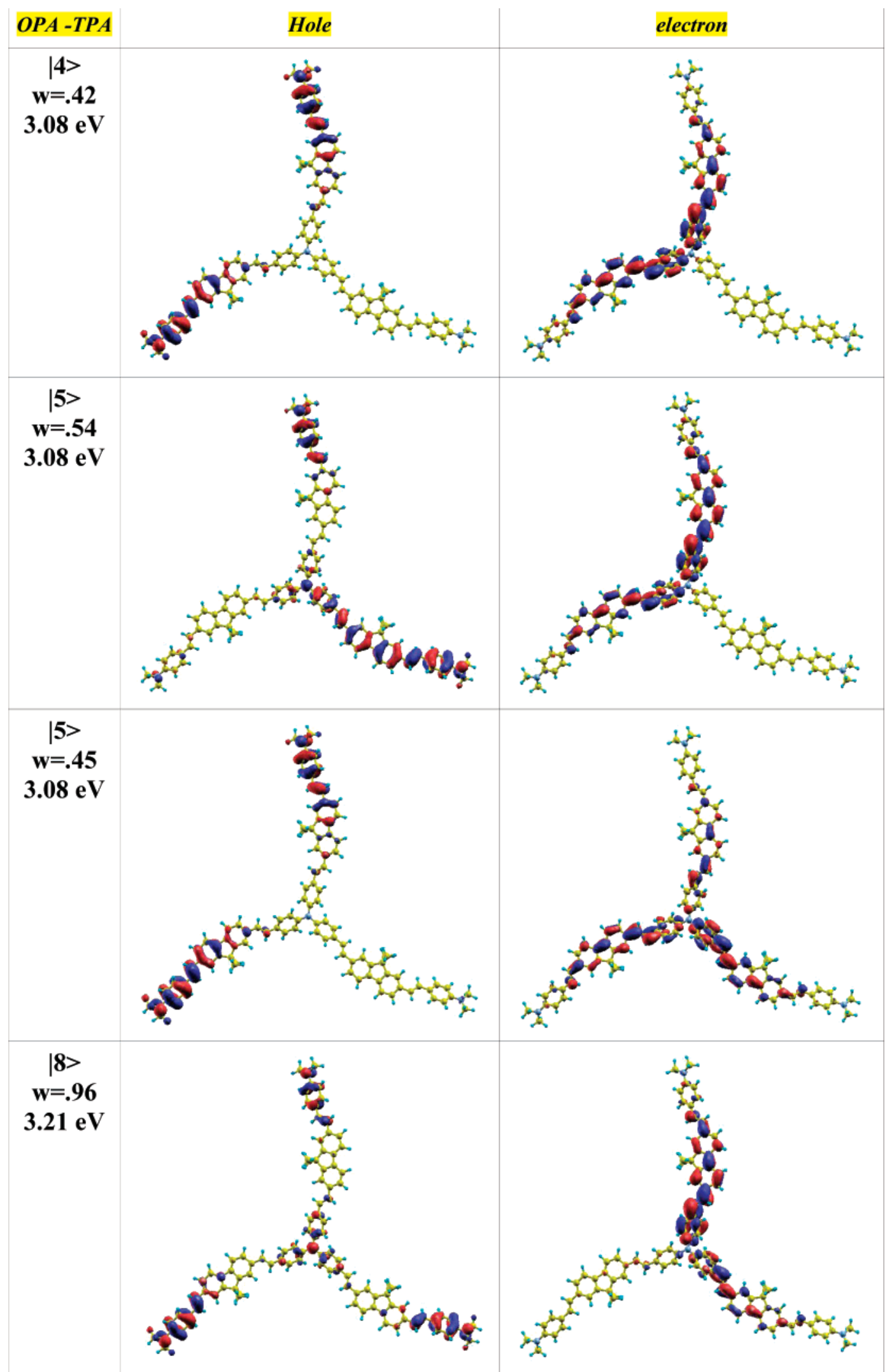

Figure 6. Part 2 of 4.

for the first two excited states, but this shift is not constant for all excited states. In addition, the finite number of excited states (54) included for the calculation of the optical properties of chromophore 4 provides converged TPA amplitudes only for the low-energy part of the spectrum which might explain the discrepancy between calculated and experimental relative amplitudes of the different TPA peaks.

It is however insightful to examine the contribution of the different excited states to the successive TPA peaks. The calculated TPA maximum near $800 \mathrm{~nm}$ lies in a region where all states 


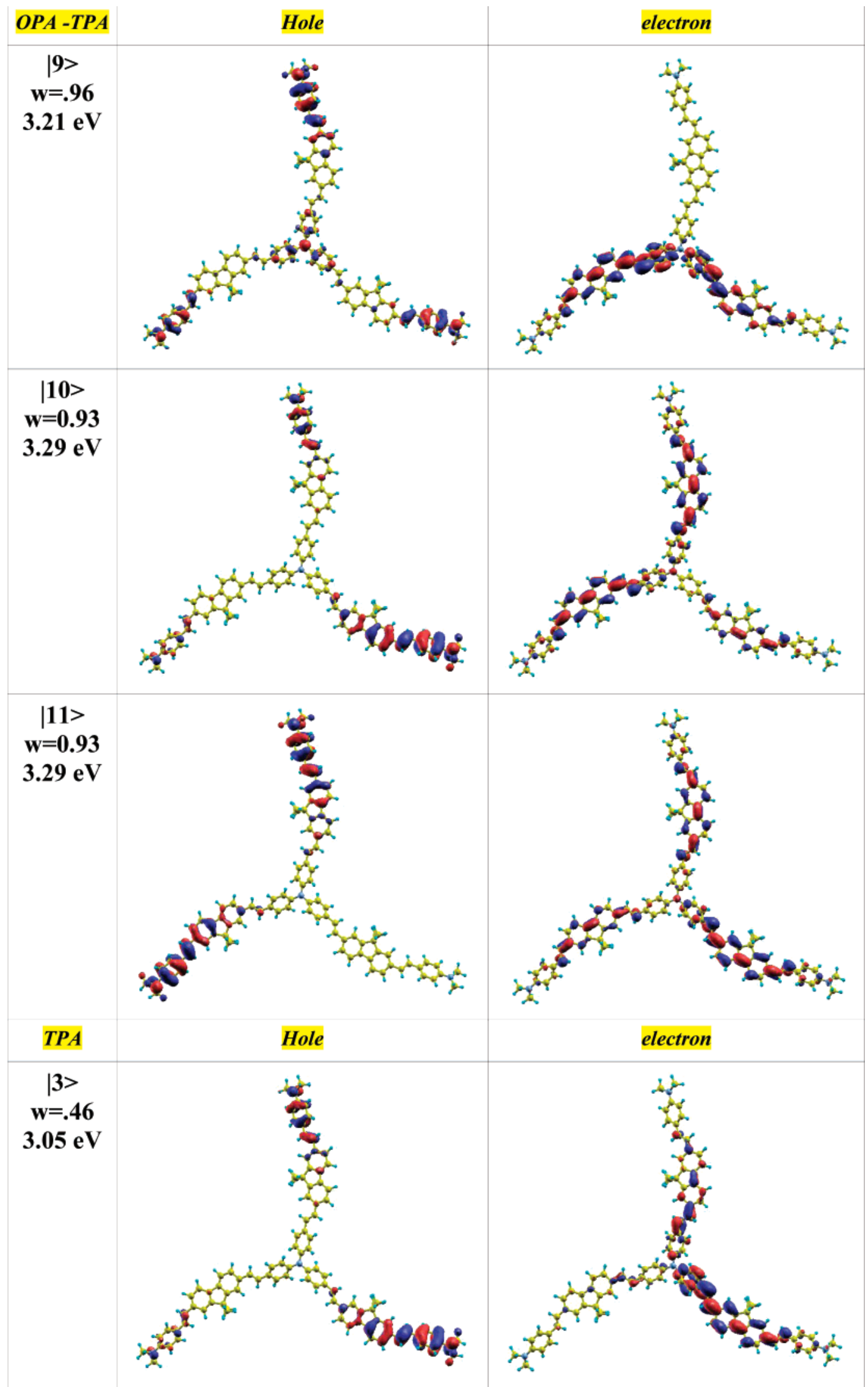

Figure 6. Part 3 of 4.

from $|3\rangle$ up to $|7\rangle$ can contribute. The largest transition dipole moments with the two degenerated OPA states is calculated for state $|6\rangle$. However, it is clear that the broad band results from contributions of several excited states. States $|4\rangle$ and $|5\rangle$ most probably contribute as virtual states as well as states $|1\rangle$ and $|2\rangle$. Actually, the transition dipole moments between the ground state and states $|4\rangle$ and $|5\rangle$, though smaller than those between the ground state and states $|1\rangle$ and $|2\rangle$, remain substantial (Table 2 ). The two next local maxima visible at lower wavelengths can be attributed to states $|12\rangle$ and $|15\rangle$, respectively. 


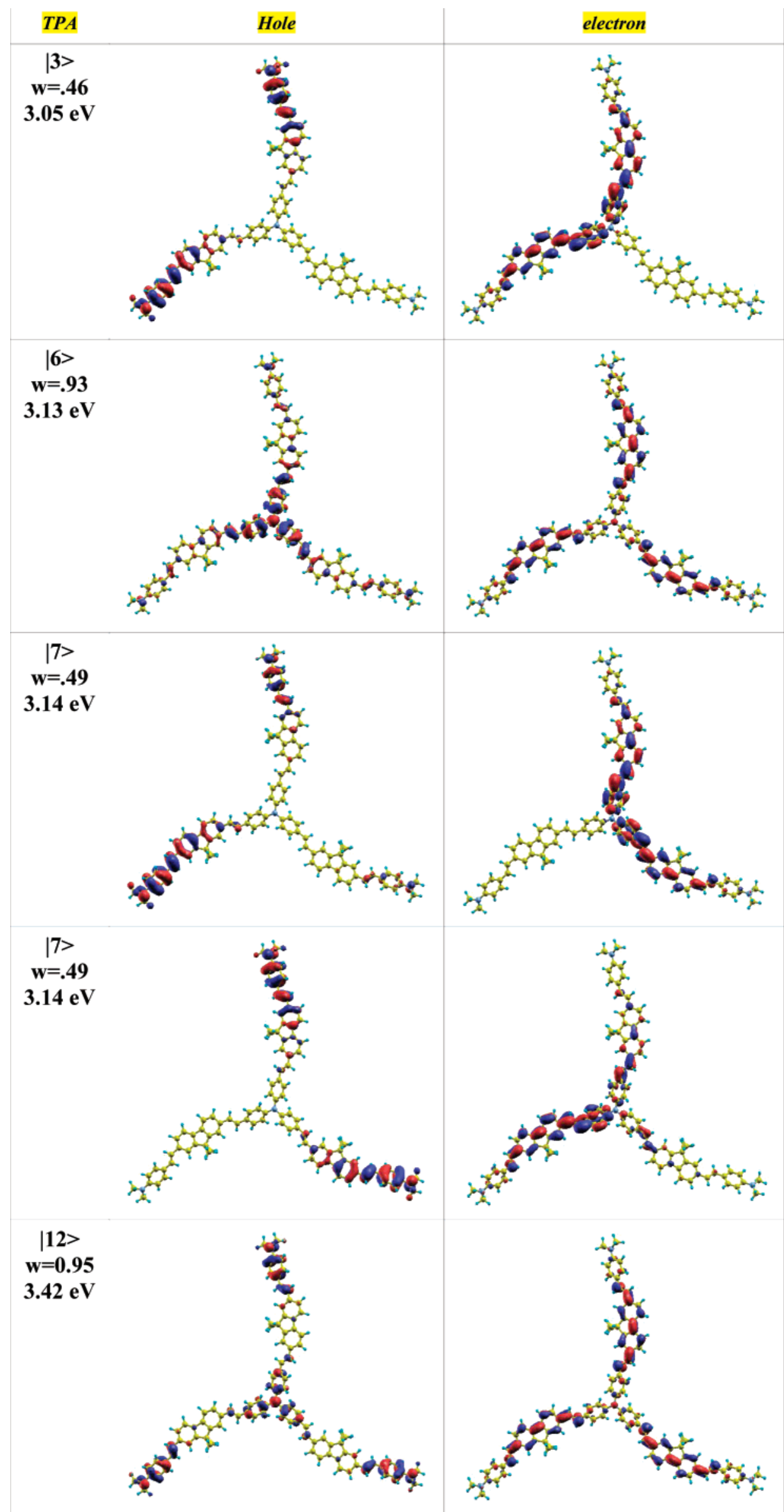

Figure 6. Part 4 of 4 . Natural transition orbitals ${ }^{104}$ of chromophore 4: emission (top panel); absorption (all others). The right panels quote in sequence excited state number, associated eigenvalues, and transition energies. 


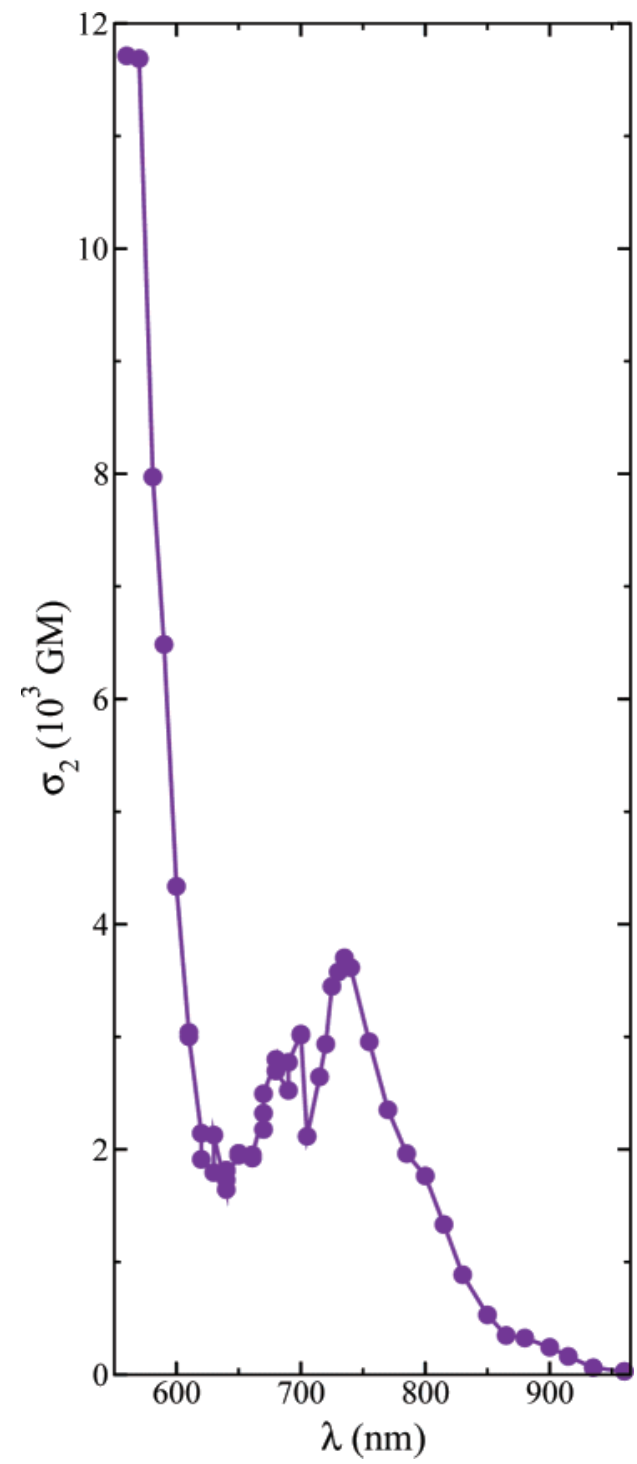

Figure 7. Experimental TPA cross section of the branched chromophore 4 in toluene.

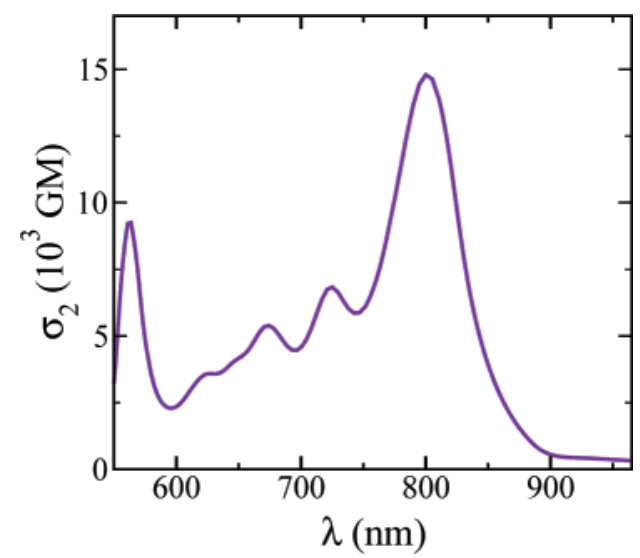

Figure 8. Calculated TPA cross section of the branched chromophore 4.

Comparison of the TPA activity of quadrupolar chromophore $\mathbf{3}$ and its three-branched analogue $\mathbf{4}$ is quite informative. As evidenced from Table 5, chromophore $\mathbf{4}$ exhibits a slightly larger intrinsic maximum TPA $\left(\sigma_{2}{ }^{\max } / N_{\text {eff }}^{2}\right)$ cross section in the NIR region than its quadrupolar branch $\mathbf{3}$, indicating that the branching strategy is also advantageous for quadrupoles. However, this enhancement is much lower than that obtained

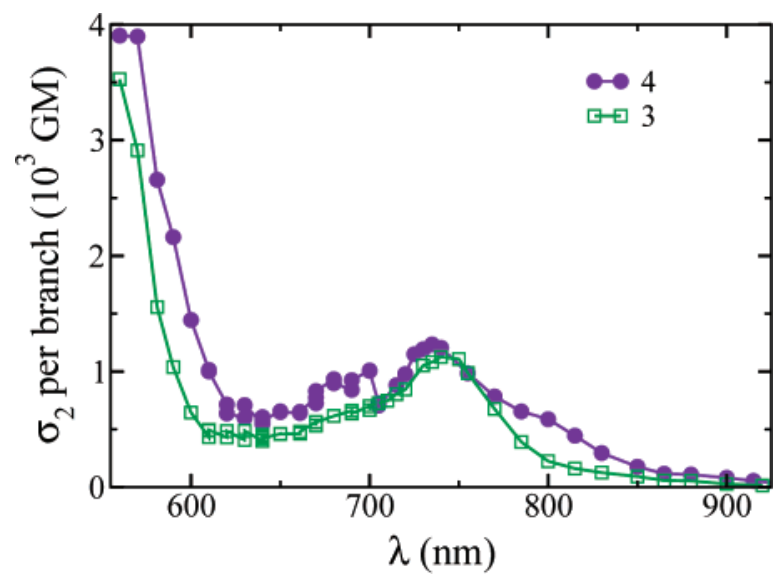

Figure 9. Experimental TPA cross section normalized for the number of branches of compounds $\mathbf{3}$ and $\mathbf{4}$ in toluene.

for an analogous series of branched chromophores built from the gathering of dipolar sub-chromophores via a common TPAmine. ${ }^{71,111}$ The effect of branching three quadrupolar chromophores can be further analyzed by comparing TPA spectra in the full spectral range (i.e., visible-NIR). As seen in Figure 9 where the TPA is normalized with respect to the number of branches, ${ }^{112}$ the TPA magnitude shows a nearly additive behavior near the first TPA maximum but a sizable enhancement on both the NIR and visible sides. This enhancement is most probably related to breaking of symmetry considerations. The almost TPA forbidden states of the quadrupolar branches mix into different excited states of dipolar character on the monomer, among which some show significant TPA activity. Even if this enhancement is not as large as that found for dipolar (instead of quadrupolar in this work) chromophores gathered via a common donating TPAmine core, the branching strategy proves to be efficient. This is especially visible in the green-yellow part of the visible spectrum due to strong TPA activity of even higher-lying excited states. As for quadrupoles, we have carefully checked that this corresponds to a true TPA process. Even if calculations are not able to provide converged TPA amplitudes in this region because of the limited number of excited states, large TPA is clearly observed near $560 \mathrm{~nm}$ in the calculated spectrum (Figure 8). This peak arises from high-lying excited states and confirms experimental observations.

\section{Conclusion}

Design of versatile NLO chromophores with broadly tunable and intense TPA spectra is a major goal of the field and an important step toward technological applications including optical limiting. In that respect, the TPA properties of the quadrupolar series investigated in the present work are of particular interest, since they show strong TPA activity in two complementary spectral regions. In addition to the NIR region where such compounds are known to be strongly active, the quadrupolar chromophores studied in this article have been demonstrated to show remarkable TPA activities in the greenyellow part of the visible spectrum due to contribution from high-lying excited states. Such two-peaked TPA spectra were predicted recently theoretically for quadrupolar arylidenepiperidone dyes. ${ }^{113}$ Interestingly, the relative magnitude of the TPA peak located in the yellow-green region is found to be even more sensitive to structural parameters (planarity of the core, nature of the linker between donating end groups and core) than the TPA peaks located in the visible red-NIR region. This 
provides useful information for the understanding and, in a further step, control of the optical limiting properties of such compounds.

In addition to substitution, branching proved to be another fruitful approach for modification of TPA properties. ${ }^{40-62}$ Although a nearly additive behavior is observed for the peak TPA responses in the NIR region of the branched compound with respect to its monomeric constituents, a substantial spectral broadening introduced by interbranch electronic coupling is observed, leading to broader TPA activity in the NIR and stronger TPA in the visible regions. Such a broadening effect is of interest for broadband optical limiting applications.

Comparison to dipolar branched systems reveals a number of remarkable trends concerning branching effects on the TPA activity. We first recall minimal TPA enhancements in the case of branched dipolar systems based on the TPBenzene core, ${ }^{72}$ where the three benzene rings are attached to the fourth in the meta position. This is well-known to lead to vanishing conjugation and ultimately inhibits interbranch cross-talk. Subsequently, the TPA response of the branched system is additive, and is only modified by interbranch electrostatic interactions, which can be adequately accounted for by the Frenkel exciton model. On the other hand, branched dipolar multichromophores based on the TPAmine core have shown important TPA enhancement that cannot be accounted for within the Frenkel excitonic model. Nevertheless, this model establishes a firm relationship between excited state structures of the branched chromophore and its building blocks. In that case, we notice that the central electrondonating core shared by three dipolar branches is subject to the electron-withdrawing influence of all three end groups, instead of only one in the monomeric counterpart. This is comparable to a monomeric unit bearing a stronger acceptor end group that is well-known to induce a larger "polarization" to the molecule. Consequently, this increases the "absolute" TPA magnitude in combination with some interbranch conjugation and wave function overlap. In contrast to the dipolar cases, the central TPAmine unit of chromophore $\mathbf{4}$ introduces noticeable dissymmetry to the quadrupolar branches. Such dissymmetry frequently reduces the effective TPA response compared to ideal quadrupoles, as we found previously, ${ }^{114}$ while the central TPAmine unit still promotes the cross-branch talk. Thus, we believe that both effects cancel each other in the case of TPAmine branched quadrupoles, leading to weak TPA enhancements, as evidenced in the case of chromophore 4. Nevertheless, the nature of the excited states contributing to both OPA and TPA responses is considerably modified by the TPAmine branching center compared to the parent monomeric quadrupole. We observe new excited states in the branched structure with asymmetric charge transfer, which effectively renders the Frenkel exciton model unusable.

Finally, the present studies provide interesting perspectives given the difference of the effect on TPA magnitude produced by the branching of chromophores on a triphenylamine core. The TPA modification induced by the branching is obviously strongly dependent on both the nature and the symmetry (quadrupolar versus dipolar) of the sub-chromophores of the resulting three-branched structure. Whereas a major enhancement of the intrinsic TPA ${ }^{108}$ (i.e., normalized by the square of the effective number of electrons) is observed in the case of the branching of strongly dipolar chomophores, ${ }^{71,111}$ branching of quadrupoles gives rise to only a slight enhancement of the intrinsic TPA magnitude of the low-energy TPA band. On the other hand, a significant enhancement is observed on both sides of this band, on both the NIR and visible sides and in the visible.
This originates from the inherent breaking of symmetry of the sub-chromophores and the contribution of a larger number of close excited states which gives rises to overlap of TPA bands originating from different states. We stress that this effective TPA broadening can be of particular interest for various applications, including TPEF imaging (due to the largest spectral band in the NIR) and optical limiting. Ultimately, this comparison and analysis suggest an exploratory route for the next level of molecular engineering for enhancement of TPA by assembling via a common core, allowing for coherent coupling $^{62,63}$ of octupolar derivatives within a branched structure. This would result in (dendritic) self-similar structures that should benefit from the significant enhancement of the intrinsic TPA. This requires of course the use of suitable conjugating acceptor joints in combination with the electron-donating TPAmine core.

Acknowledgment. We wish to thank Dr. Francesca Terenziani for stimulating discussions and Dr. M. Drobizhev and A. Rebane for suggesting BDPAS as an additional TPEF standard and providing a sample of the material as well as the TPA cross section data. M.B.-D. and S.T. gratefully acknowledge CNRS for an invited research associate position to S.T. This work was performed in part at the US Department of Energy, Center for Integrated Nanotechnologies (CINT), at Los Alamos National Laboratory (LANL) (contract DE-AC52-06NA25396). We also acknowledge support of Center for Nonlinear Studies (CNLS) at LANL. The work at UCL was supported by the UK Engineering and Physical Sciences Research Council (EPSRC). A portion of the calculations was funded by the "Centre Informatique National de l'Enseignement Supérieur" (CINESFrance).

Supporting Information Available: Experimental absorption and emission spectra and calculated absorption spectra of 1-4, plot of the original and refined values for the action cross sections of fluorescein and corresponding two-photon absorption cross section spectra of $\mathbf{1 - 3}$, comparison of one- and twophoton spectra of $\mathbf{4}$, as well as natural transition orbitals of $\mathbf{1}$ and 2. This material is available free of charge via the Internet at http://pubs.acs.org.

\section{References and Notes}

(1) Strehmel, B.; Strehmel, V. Adv. Photochem. 2007, 29, 111-354.

(2) Denk, W.; Strickler, J. H.; Webb, W. W. Science 1990, 248, 7376.

(3) Xu, C.; Zipfel, W.; Shear, J. B.; Williams, R. M.; Webb, W. W. Proc. Natl. Acad. Sci. U.S.A. 1996, 93, 10763-10768.

(4) He, G. S.; Xu, G. C.; Prasad, P. N.; Reinhardt, B. A.; Bhatt, J. C.; McKellar, R.; Dillard, A. G. Opt. Lett. 1995, 20, 435-437.

(5) Ehrlich, J. E.; Wu, X. L.; Lee, I. Y. S.; Hu, Z. Y.; Röckel, H.; Marder, S. R.; Perry, J. W. Opt. Lett. 1997, 22, 1843-1845.

(6) Maruo, S.; Nakamura, O.; Kawata, S. Opt. Lett. 1997, 22, 132134.

(7) Cumpston, B. H.; Ananthavel, S. P.; Barlow, S.; Dyer, D. L.; Ehrlich, J. E.; Erskine, L. L.; Heikal, A. A.; Kuebler, S. M.; Lee, I.-Y. S.; McCord-Maughon, D.; Qin, J.; Röckel, H.; Rumi, M.; Wu, X. L.; Marder, S. R.; Perry, J. W. Nature 1999, 398, 51-54.

(8) Kawata, S.; Sun, H.-B.; Tanaka, T.; Takada, K. Nature 2001, 412, 697-698.

(9) He, G. S.; Bhawalkar, J. D.; Zhao, C. F.; Prasad, P. N. Appl. Phys. Lett. 1995, 67, 2433-2435.

(10) He, G. S.; Yuan, L.; Cheng, N.; Bhawalkar, J. D.; Prasad, P. N.; Brott, L. L.; Clarson, S. J.; Reinhardt, B. A. J. Opt. Soc. Am. B 1997, 14, 1079-1087.

(11) Reinhardt, B. A.; Brott, L. L.; Clarson, S. J.; Dillard, A. G.; Bhatt, J. C.; Kannan, R.; Yuan, L.; He, G. S.; Prasad, P. N. Chem. Mater. 1998, 10, $1863-1874$

(12) Belfield, K. D.; Hagan, D. J.; Van Stryland, E. W.; Schafer, K. J.; Negres, R. A. Org. Lett. 1999, 1, 1575-1578.

(13) Abbotto, A.; Beverina, L.; Bozio, R.; Bradamante, S.; Ferrante, C.; Pagani, G. A.; Signorini, R. Adv. Mater. 2000, 12, 1963-1967. 
(14) Liu, Z.-q.; Fang, Q.; Wang, D.; Cao, D.-x.; Xue, G.; Yu, W.-t.; Lei, H. Chem.-Eur. J. 2003, 9, 5074-5084.

(15) Charier, S.; Ruel, O.; Baudin, J.-B.; Alcor, D.; Allemand, J.-F.; Meglio, A.; Jullien, L. Angew. Chem., Int. Ed. 2004, 43, 4785-4788.

(16) Albota, M.; Beljonne, D.; Brédas, J.-L.; Ehrlich, J. E.; Fu, J.-Y.; Heikal, A. A.; Hess, S. E.; Kogej, T.; Levin, M. D.; Marder, S. R.; McCordMaughon, D.; Perry, J. W.; Röckel, H.; Rumi, M.; Subramaniam, G.; Webb, W. W.; Wu, X.-L.; Xu, C. Science 1998, 281, 1653-1656.

(17) Ventelon, L.; Moreaux, L.; Mertz, J.; Blanchard-Desce, M. Chem. Commun. 1999, 2055-2056.

(18) Kim, O.-K.; Lee, K.-S.; Woo, H. Y.; Kim, K.-S.; He, G. S.; Swiatkiewicz, J.; Prasad, P. N. Chem. Mater. 2000, 12, 284-286.

(19) Rumi, M.; Ehrlich, J. E.; Heikal, A. A.; Perry, J. W.; Barlow, S.; Hu, Z.-Y.; McCord-Maughon, D.; Parker, T. C.; Röckel, H.; Thayumanavan, S.; Marder, S. R.; Beljonne, D.; Brédas, J.-L. J. Am. Chem. Soc. 2000, $122,9500-9510$

(20) Ventelon, L.; Charier, S.; Moreaux, L.; Mertz, J.; Blanchard-Desce, M. Angew. Chem., Int. Ed. 2001, 40, 2098-2101.

(21) Frederiksen, P. K.; Jørgensen, M.; Ogilby, P. R. J. Am. Chem. Soc. 2001, 123, 1215-1221.

(22) Mongin, O.; Porrès, L.; Moreaux, L.; Mertz, J.; Blanchard-Desce, M. Org. Lett. 2002, 4, 719-722.

(23) Abbotto, A.; Beverina, L.; Bozio, R.; Facchetti, A.; Ferrante, C.; Pagani, G. A.; Pedron, D.; Signorini, R. Org. Lett. 2002, 4, 1495-1498.

(24) Pond, S. J. K.; Rumi, M.; Levin, M. D.; Parker, T. C.; Beljonne, D.; Day, M. W.; Brédas, J.-L.; Marder, S. R.; Perry, J. W. J. Phys. Chem. A 2002, 106, 11470-11480.

(25) Blanchard-Desce, M. C. R. Phys. 2002, 3, 439-448.

(26) Yang, W. J.; Kim, D. Y.; Jeong, M.-Y.; Kim, H. M.; Jeon, S.-J.;

Cho, B. R. Chem. Commun. 2003, 2618-2619.

(27) Strehmel, B.; Sarker, A. M.; Detert, H. ChemPhysChem 2003, 4 249-259.

(28) Yang, W. J.; Kim, C. H.; Jeong, M.-Y.; Lee, S. K.; Piao, M. J.; Jeon, S.-J.; Cho, B. R. Chem. Mater. 2004, 16, 2783-2789.

(29) Werts, M. H. V.; Gmouh, S.; Mongin, O.; Pons, T.; BlanchardDesce, M. J. Am. Chem. Soc. 2004, 126, 16294-16295.

(30) Kim, H. M.; Jeong, M.-Y.; Ahn, H. C.; Jeon, S.-J.; Cho, B. R. J. Org. Chem. 2004, 69, 5749-5751.

(31) Pond, S. J. K.; Tsutsumi, O.; Rumi, M.; Kwon, O.; Zojer, E.; Brédas, J.-L.; Marder, S. R.; Perry, J. W. J. Am. Chem. Soc. 2004, 126, 92919306.

(32) Belfield, K. D.; Morales, A. R.; Kang, B.-S.; Hales, J. M.; Hagan, D. J.; Van Stryland, E. W.; Chapela, V. M.; Percino, J. Chem. Mater. 2004, $16,4634-4641$

(33) Liu, Z.-Q.; Fang, Q.; Cao, D.-X.; Wang, D.; Xu, G.-B. Org. Lett. 2004, 6, 2933-2936.

(34) Lee, S. K.; Yang, W. J.; Choi, J. J.; Kim, C. H.; Jeon, S.-J.; Cho, B. R. Org. Lett. 2005, 7, 323-326.

(35) Charlot, M.; Porres, L.; Entwistle, C. D.; Beeby, A.; Marder, T B.; Blanchard-Desce, M. Phys. Chem. Chem. Phys. 2005, 7, 600-606.

(36) Chung, S.-J.; Rumi, M.; Alain, V.; Barlow, S.; Perry, J. W.; Marder, S. R. J. Am. Chem. Soc. 2005, 127, 10844-10845.

(37) Woo, H. Y.; Liu, B.; Kohler, B.; Korystov, D.; Mikhailovsky, A.; Bazan, G. C. J. Am. Chem. Soc. 2005, 127, 14721-14729.

(38) Strehmel, V.; Sarker, A. M.; Lahti, P. M.; Karasz, F. E.; Heydenreich, M.; Wetzel, H.; Haebel, S.; Strehmel, B. ChemPhysChem 2005, 6 , $267-276$

(39) Mongin, O.; Porrès, L.; Charlot, M.; Katan, C.; Blanchard-Desce, M. Chem.-Eur. J. 2007, 13, 1481-1498.

(40) Joshi, M. P.; Swiatkiewicz, J.; Xu, F.; Prasad, P. N.; Reinhardt, B. A.; Kannan, R. Opt. Lett. 1998, 23, 1742-1744.

(41) Chung, S.-J.; Kim, K.-S.; Lin, T.-C.; He, G. S.; Swiatkiewicz, J.; Prasad, P. N. J. Phys. Chem. B 1999, 103, 10741-10745.

(42) He, G. S.; Swiatkiewicz, J.; Jiang, Y.; Prasad, P. N.; Reinhardt, B. A.; Tan, L.-S.; Kannan, R. J. Phys. Chem. A 2000, 104, 4805-4810.

(43) Adronov, A.; Fréchet, J. M. J.; He, G. S.; Kim, K.-S.; Chung, S.J.; Swiatkiewicz, J.; Prasad, P. N. Chem. Mater. 2000, 12, 2838-2841.

(44) Chung, S.-J.; Lin, T.-C.; Kim, K.-S.; He, G. S.; Swiatkiewicz, J.; Prasad, P. N.; Baker, G. A.; Bright, F. V. Chem. Mater. 2001, 13, 40714076.

(45) Drobizhev, M.; Karotki, A.; Rebane, A.; Spangler, C. W. Opt. Lett. 2001, 26, 1081-1083.

(46) Cho, B. R.; Son, K. H.; Lee, S. H.; Song, Y.-S.; Lee, Y.-K.; Jeon, S.-J.; Choi, J. H.; Lee, H.; Cho, M. J. Am. Chem. Soc. 2001, 123, 1003910045

(47) Beljonne, D.; Wenseleers, W.; Zojer, E.; Shuai, Z.; Vogel, H.; Pond, S. J. K.; Perry, J. W.; Marder, S. R.; Brédas, J.-L. Adv. Funct. Mater. 2002, 12, 631-641.

(48) Mongin, O.; Brunel, J.; Porrès, L.; Blanchard-Desce, M. Tetrahedron Lett. 2003, 44, 2813-2816.

(49) Mongin, O.; Porrès, L.; Katan, C.; Pons, T.; Mertz, J.; BlanchardDesce, M. Tetrahedron Lett. 2003, 44, 8121-8125.
(50) Abbotto, A.; Beverina, L.; Bozio, R.; Facchetti, A.; Ferrante, C. Pagani, G. A.; Pedron, D.; Signorini, R. Chem. Commun. 2003, 21442145.

(51) Drobizhev, M.; Karotki, A.; Dzenis, Y.; Rebane, A.; Suo, Z.; Spangler, C. W. J. Phys. Chem. B 2003, 107, 7540-7543.

(52) Yoo, J.; Yang, S. K.; Jeong, M.-Y.; Ahn, H. C.; Jeon, S.-J.; Cho, B. R. Org. Lett. 2003, 5, 645-648.

(53) Brousmiche, D. W.; Serin, J. M.; Fréchet, J. M. J.; He, G. S.; Lin, T.-C.; Chung, S. J.; Prasad, P. N. J. Am. Chem. Soc. 2003, 125, $1448-$ 1449.

(54) Porrès, L.; Mongin, O.; Katan, C.; Charlot, M.; Pons, T.; Mertz, J.; Blanchard-Desce, M. Org. Lett. 2004, 6, 47-50.

(55) Porrès, L.; Katan, C.; Mongin, O.; Pons, T.; Mertz, J.; BlanchardDesce, M. J. Mol. Struct. 2004, 704, 17-24.

(56) Porrès, L.; Mongin, O.; Katan, C.; Charlot, M.; Bhatthula, B. K. G.; Jouikov, V.; Pons, T.; Mertz, J.; Blanchard-Desce, M. J. Nonlinear Opt. Phys. 2004, 13, 451-460.

(57) Bartholomew, G. P.; Rumi, M.; Pond, S. J. K.; Perry, J. W.; Tretiak, S.; Bazan, G. C. J. Am. Chem. Soc. 2004, 126, 11529-11542.

(58) Le Droumaguet, C.; Mongin, O.; Werts, M. H. V.; Blanchard-Desce, M. Chem. Commun. 2005, 2802-2804.

(59) Terenziani, F.; Morone, M.; Gmouh, S.; Blanchard-Desce, M. ChemPhysChem 2006, 7, 685-696.

(60) Mongin, O.; Krishna, T. R.; Werts, M. H. V.; Caminade, A.-M.; Majoral, J.-P.; Blanchard-Desce, M. Chem. Commun. 2006, 915-917.

(61) Bhaskar, A.; Ramakrishna, G.; Lu, Z.; Twieg, R.; Hales, J. M.; Hagan, D. J.; Van Stryland, E.; Goodson, T., III. J. Am. Chem. Soc. 2006 $128,11840-11849$

(62) Varnavski, O.; Yan, X.; Mongin, O.; Blanchard-Desce, M.; Goodson, T., III. J. Phys. Chem. C 2007, 111, 149-162.

(63) Katan, C.; Terenziani, F.; Mongin, O.; Werts, M. H. V.; Porrès, L.; Pons, T.; Mertz, J.; Tretiak, S.; Blanchard-Desce, M. J. Phys. Chem. A 2005, 109, 3024-3037

(64) Swiatkiewicz, J.; Prasad, P. N.; Reinhardt, B. A. Opt. Commun. 1998, 157, 135-138.

(65) This is, for instance, the case for several compounds which have been reported to show giant $\sigma_{2}$ values at a wavelength where one-photon absorption is also present. ${ }^{66-69}$

(66) Rath, H.; Sankar, J.; PrabhuRaja, V.; Chandrashekar, T. K.; Nag,

A.; Goswami, D. J. Am. Chem. Soc. 2005, 127, 11608-11609.

(67) Misra, R.; Kumar, R.; Chandrashekar, T. K.; Nag, A.; Goswami, D. Org. Lett. 2006, 8, 629-631.

(68) Kim, D. Y.; Ahn, T. K.; Kwon, J. H.; Kim, D.; Ikeue, T.; Aratani, N.; Osuka, A.; Shigeiwa, M.; Maeda, S. J. Phys. Chem. A 2005, 109, 29962999.

(69) Ahn, T. K.; Kim, K. S.; Kim, D. Y.; Noh, S. B.; Aratani, N.; Ikeda, C.; Osuka, A.; Kim, D. J. Am. Chem. Soc. 2006, 128, 1700-1704.

(70) Goodson, T. G., III. Acc. Chem. Res. 2005, 38, 99-107.

(71) Katan, C.; Terenziani, F.; Le Droumaguet, C.; Mongin, O.; Werts, M. H. V.; Tretiak, S.; Blanchard-Desce, M. Proc. SPIE-Int. Soc. Opt. Eng. 2005, 5935, 13-27.

(72) Terenziani, F.; Le Droumaguet, C.; Katan, C.; Mongin, O.; Blanchard-Desce, M. ChemPhysChem 2007, 8, 723-734.

(73) Davidov, A. S. Theory of molecular excitons; Plenum Press: New York, 1971

(74) Silinsh, E. A.; Capek, V. Organic Molecular Crystals: Interaction, Localization, and Transport Phenomena; AIP Press: New York, 1994.

(75) Verbouwe, W.; Viaene, L.; Van der Auweraer, M.; De Schryver, F. C.; Masuhara, H.; Pansu, R.; Faure, J. J. Phys. Chem. A 1997, 101, 81578165 .

(76) Verbouwe, W.; Van der Auweraer, M.; De Schryver, F. C.; Piet, J. J.; Warman, J. M. J. Am. Chem. Soc. 1998, 120, 1319-1324.

(77) Varnavski, O. P.; Ostrowski, J. C.; Sukhomlinova, L.; Twieg, R. J.; Bazan, G. C.; Goodson, T., III. J. Am. Chem. Soc. 2002, 124, 17361743 .

(78) Lahankar, S. A.; West, R.; Varnavski, O.; Xie, X.; Goodson, T., III; Sukhomlinova, L.; Twieg, R. J. Chem. Phys. 2004, 120, 337-344.

(79) Demas, J. N.; Crosby, G. A. J. Phys. Chem. 1971, 75, 991-1024

(80) Eaton, D. F. Pure Appl. Chem. 1988, 60, 1107-1114.

(81) Kennedy, S. M.; Lytle, F. E. Anal. Chem. 1986, 58, 2643-2647.

(82) Overway, K. S.; Lytle, F. E. Appl. Spectrosc. 1998, 52, 298-302.

(83) Xu, C.; Webb, W. W. J. Opt. Soc. Am. B 1996, 13, 481-491.

(84) Albota, M. A.; Xu, C.; Webb, W. W. Appl. Opt. 1998, 37, 73527356.

(85) Werts, M. H. V.; Nerambourg, N.; Pélégry, D.; Le Grand, Y.; Blanchard-Desce, M. Photochem. Photobiol. Sci. 2005, 4, 531-538.

(86) Marsh, R. J.; Armoogum, D. A.; Bain, A. J. Chem. Phys. Lett. 2002, $366,398-405$

(87) Drobizhev, M.; Rebane, A.; Suo, Z.; Spangler, C. W. J. Lumin. $\mathbf{2 0 0 5}, 111,291-305$

(88) Frisch, M. J.; Trucks, G. W.; Schlegel, H. B.; Scuseria, G. E.; Robb, M. A.; Cheeseman, J. R.; Montgomery, J. A., Jr.; Vreven, T.; Kudin, K. N.; Burant, J. C.; Millam, J. M.; Iyengar, S. S.; Tomasi, J.; Barone, V.; 
Mennucci, B.; Cossi, M.; Scalmani, G.; Rega, N.; Petersson, G. A.; Nakatsuji, H.; Hada, M.; Ehara, M.; Toyota, K.; Fukuda, R.; Hasegawa, J.; Ishida, M.; Nakajima, T.; Honda, Y.; Kitao, O.; Nakai, H.; Klene, M.; Li, X.; Knox, J. E.; Hratchian, H. P.; Cross, J. B.; Bakken, V.; Adamo, C.; Jaramillo, J.; Gomperts, R.; Stratmann, R. E.; Yazyev, O.; Austin, A. J.; Cammi, R.; Pomelli, C.; Ochterski, J. W.; Ayala, P. Y.; Morokuma, K.; Voth, G. A.; Salvador, P.; Dannenberg, J. J.; Zakrzewski, V. G.; Dapprich, S.; Daniels, A. D.; Strain, M. C.; Farkas, O.; Malick, D. K.; Rabuck, A. D.; Raghavachari, K.; Foresman, J. B.; Ortiz, J. V.; Cui, Q.; Baboul, A. G.; Clifford, S.; Cioslowski, J.; Stefanov, B. B.; Liu, G.; Liashenko, A.; Piskorz, P.; Komaromi, I.; Martin, R. L.; Fox, D. J.; Keith, T.; Al-Laham, M. A.; Peng, C. Y.; Nanayakkara, A.; Challacombe, M.; Gill, P. M. W.; Johnson, B.; Chen, W.; Wong, M. W.; Gonzalez, C.; Pople, J. A. Gaussian 98, revision A.11, and Gaussian 03, revision D.02; Gaussian, Inc.: Wallingford, CT, 2004.

(89) Masunov, A.; Tretiak, S. J. Phys. Chem. B 2004, 108, 899-907. (90) Wu, C.; Tretiak, S.; Chernyak, V. Y. Chem. Phys. Lett. 2007, 433, $305-311$.

(91) Magyar, R. J.; Tretiak, S. J. Chem. Theory Comput. 2007, 3, 976987.

(92) Grimme, S.; Parac, M. ChemPhysChem 2003, 4, 292-295.

(93) Pogantsch, A.; Heimel, G.; Zojer, E. J. Chem. Phys. 2002, 117, $5921-5928$

(94) Dreuw, A.; Weisman, J. L.; Head-Gordon, M. J. Chem. Phys. 2003, 119, 2943-2946 4016.

(95) Dreuw, A.; Head-Gordon, M. J. Am. Chem. Soc. 2004, 126, 4007-

(96) Casida, M. E.; Jamorski, C.; Casida, K. C.; Salahub, D. R. J. Chem. Phys. 1998, 108, 4439-4449.

(97) Furche, F.; Ahlrichs, R. J. Chem. Phys. 2002, 117, 7433-7447. 659 .

(98) Onida, G.; Reining, L.; Rubio, A. Rev. Mod. Phys. 2002, 74, 601-

(99) Tretiak, S.; Chernyak, V. J. Chem. Phys. 2003, 119, 8809-8823.
(100) Kobko, N.; Masunov, A.; Tretiak, S. Chem. Phys. Lett. 2004, 392, $444-451$.

(101) Garito, A. F.; Heflin, J. R.; Wong, K. Y.; Zamani-Khamiri, O. In Organic Materials for Non-linear Optics; Hann, R. A., Bloor, D., Eds.; Royal Society of Chemistry: London, 1989; pp 16-27.

(102) Ahlrichs, R.; Bär, M.; Häser, M.; Horn, H.; Kölmel, C. Chem. Phys. Lett. 1989, 162, 165-169.

(103) Meystre, P.; Sargent, M., III. Elements of Quantum Optics, 2nd ed.; Springer-Verlag: Berlin, Heidelberg, New York, 1991.

(104) Martin, R. L. J. Chem. Phys. 2003, 118, 4775-4777.

(105) Kokalj, A. J. Mol. Graphics Modell. 2000, 17, 176-179.

(106) Champagne, B.; Perpete, E. A.; Jacquemin, D.; Van Gisbergen, S. J. A.; Baerends, E.-J.; Soubra-Ghaoui, C.; Robins, K. A.; Kirtman, B. J. Phys. Chem. A 2000, 104, 4755-4763.

(107) Kuzyk, M. G. J. Chem. Phys. 2003, 119, 8327-8334.

(108) Perez Moreno, J.; Kuzyk, M. G. J. Chem. Phys. 2005, 123, 194101.

(109) Charlot, M.; Izard, N.; Mongin, O.; Riehl, D.; Blanchard-Desce, M. Chem. Phys. Lett. 2006, 417, 297-302.

(110) In combination with excited state absorption, since optical limitation experiments were conducted using nanosecond pulses, thus allowing for excited state absorption to occur during the laser pulse.

(111) Estimation of the intrinsic TPA of compounds $\mathbf{1 b}$ (dipole) and 3b (octupole) reported in ref 71 gives $\sigma_{2}{ }^{\text {max }} / N_{\text {eff }}^{2}$ values of, respectively, 0.43 and 1.75 , which is a major enhancement.

(112) The branching effect can be analyzed in terms of number of branches or effective number of electrons, which gives exactly the same picture in that particular case (due to the definition of $N_{\text {eff }}{ }^{107}$ for TPAmine compounds, $N_{\mathrm{eff}}^{2}$ is proportional to the number of branches).

(113) Badaeva, E. A.; Timofeeva, T. V.; Masunov, A.; Tretiak, S. J. Phys. Chem. A 2005, 109, 7276-7284.

(114) Charlot, M.; Katan, C.; Mongin, O.; Blanchard-Desce, M. Unpublished results. 